\title{
La camisa en la indumentaria salmantina: Características, evolución y connotaciones sociales ${ }^{1}$
}

\author{
The Shirt in the clothing of Salamanca: \\ Characteristics, Evolution, and Social Overtones
}

\author{
Antonio Cea Gutiérrez \\ Instituto de Lengua, Literatura y Antropología, \\ CSIC, Madrid \\ A la memoria de Don Julio Caro Baroja \\ en el centenario de su nacimiento
}

\section{RESUMEN}

La camisa, elemento fundamental de la indumentaria, tiene su lugar en el cuerpo entre las piezas interiores que componen el remudo. Documentada en los protocolos notariales serranos desde la segunda mitad del siglo XVI, aparece en los primeros años como de uso indistinto para el hombre y la mujer, utilizándose paulatinamente y de manera generalizada el término camisón como prenda masculina y manteniéndose el de camisa para la mujer. Se estudia su evolución y características en las comarcas salmantinas de Sierra de Francia y Candelario, atendiendo a las siguientes premisas: lugares, años y número de veces en que se cita; precios en que se estima y fábricas en que se realiza; partes, elementos y nombres; estado de conservación y guarnición (materiales del bordado, labores, colores y técnicas).

Palabras clave: Camisa, Indumentaria, Moda, Patrimonio, Salamanca, España, Siglos XVI-XX.

\section{SUMMARY}

The shirt, a basic clothing article, finds its way in the body among the garments that make up the remudo. Mentioned in notarial documents from the highlands from the $2^{\text {nd }}$ half of the $16^{\text {th }}$ century on, the shirt was first used by both men and women indistinctly. As time passed, the term camisón became gradually applied to the garment worn generally by men, whereas camisa kept being employed in reference to women's clothing. The author here discusses the characteristics and evolution of the article in such regions in the province of Salamanca as Sierra de Francia and Candelario according to the following premises: places, years, and number of times cited; prices at which it was valued and factories in which it was made; parts, elements, and names; state of preservation and adornment (embroidery materials, sewing \& knitting, colors, and techniques).

Key words: Shirt, Clothing, Fashion, Heritage, Salamanca, Spain, $16^{\text {th }}$ to $20^{\text {th }}$ centuries.

\footnotetext{
${ }^{1}$ Una primera versión de este trabajo fue presentada en II Jornadas sobre el traje Popular: claves y procesos, Pervivencias de elementos históricos en la indumentaria española. Madrid: Ministerio de Cultura, Museo del Traje (13-14 de octubre de 2010) No se publicaron las Actas.
} 
El seguimiento de esta prenda en su doble versión (masculina y femenina) desde los primeros documentos en el siglo XVI hasta su fosilización en el XIX, hace posible secuenciar en cada periodo las casi imperceptibles diferencias locales, especialmente a través de diversas tendencias en el empleo de los colores de sus bordados (González 1944).

Los ejemplos de "prendas-testigo" que han sobrevivido como modalidad masculina en estas comarcas, serrana y candelaria, posibilitan el estudio de la evolución del collar o cabezones del camisón desde la fórmula de las valonas y no desde la lechuguilla (que es el camino que ha seguido el resto de las comarcas salmantinas). En la variante de mujer resalta la deslumbrante ornamentación — geométrica, fitomorfa y zoomorfa - en los cabezones y mangas de la "camisa galana".

Aunque esta prenda mantiene, a lo largo del periodo que estudiamos, unas características generales más o menos fijas, es posible señalar al mismo tiempo, por siglos y géneros, una trayectoria de diferenciación sutil que se aprecia, tanto en la documentación de archivo, como en la iconografía y en las piezas-testigo conservadas. Las tendencias arcaizantes en algunos ejemplos donde se describe la hechura de la camisa "al estilo del lugar" contrastan con el carácter innovador, más a la moda, de las que se mandan hacer "a uso de ciudadanas". Resaltamos, finalmente, la importancia que se da a la utilización diaria y festiva de la camisa para el estudio de la indumentaria y su presencia sobre todo en inventarios, cartas de dote, almonedas, mandas y testamentos, así como los datos que nos proporciona esta pieza sobre la sociedad que la utiliza. Señalamos también el papel simbólico y moralizante que tradicionalmente ha desempeñado la camisa como una segunda piel, en especial en la literatura de los Siglos de Oro y a través del Cancionero y del Refranero (Cea 202: 101-136).

\section{METODOLOGÍA Y FUENTES}

- Documentos de archivo, que nos facilitan una visión diacrónica sobre más de veinte poblaciones, desde 1585 hasta 1853; 288 años de vida documental de la camisa en 1.570 ejemplos.

- Textos de tradición oral y refranes donde se expresan las connotaciones sociales y de carácter moral que popularmente se han atribuido a esta prenda.

- Iconografia: pintura, escultura, grabados y dibujos que reconstruyen la evolución de la camisa y su ornamentación, dando forma a los ejemplos documentales (Bernis 1957, 1978-1979. Cea 1983: 183-194 y 2008: 33-34. Id. 1986: 117-185).

\section{- Las piezas o prendas-testigo y las entrevistas de campo ${ }^{2}$}

\footnotetext{
${ }^{2}$ Me parece práctico recordar en esquema la estructura y familias de la indumentaria en relación a las partes del cuerpo en que se alojan las prendas, desde la cabeza a los pies, y desde fuera hacia dentro. El vestido llamado "de pies a cabeza" se compone de Tocados (tocas, garvines, sombreros, gorras, monteras y cofias). Cuerpos o prendas "de cintura para arriba" (sayuelos, jubones, chalecos, cotillas, coletos, chaquetas). Ceñidores o "prendas ceñideras" (cordones, cintas de ceñir, cintos, fajas). Prendas "de cintura para abajo" en la mujer, manteos, zagalejos y sayas), y «Prendas calzaderas» que los hombres visten por los pies (zaragüelles, valones, bragas, calzones, calzas y medias calzas y pantalones). Calzado o calcixo zapatas y zapatos, abarcas, botas y botines). Los órdenes o capas de cebolla que forman las ropas en el cuerpo se clasifican por su colocación en prendas cimeras (en el hombre las capas, anguarinas, abrigos y en la
} 
En el análisis deben tenerse siempre en cuenta las siguientes constantes:

- Lugar y procedencia, año de aparición y desaparición de la prenda, número de veces o porcentaje en que se documenta.

- Voces con que se denomina y elementos de que se compone.

- Fábrica y calidades (ordinaria o basta, entrefina y fina) según el número de hilos por vara en la urdimbre.

- Colores, guarnición, medidas y precio.

- Usos que recibe y estado de conservación.

- Clasificación atendiendo al calendario laboral y festivo (prenda cotidiana, dominguera, de media fiesta y de gran fiesta o "galas").

- Uso personalizado: "de bautismo" o de "acristianar", "de los pregones", "de vistas", de "boda", y "de luto" o "ventioseno".

- Según las tendencias in, o retro: "al estilo del país" o tal "como se acostumbra a gastar en esta tierra", y "a uso de ciudadanos" (Cea 1991: 9-211 y 2003: 15-42).

En el caso que nos ocupa de la camisa, una de las dificultades que comporta la lectura de algunos documentos es el de la imposibilidad de "traducir" en ellos el género, quedando descrita la prenda como camisa sin más. Otras veces se especifica la camisa como "de mujer", "de hombre" o "camisón", "de niños" o "de muchachos", "de niña" y "de muchacha", "de niño" y "del muchacho". Aunque no son salvables las diferencias formales entre los dos géneros, la camisa contiene en ambos casos los mismos elementos, con variaciones en la guarnición y en lógicos detalles formales. A veces la indefinición de género en los documentos dificulta su coloratura a la hora de las conclusiones (Id. 2005: 206-207).

Era mi intención completar este estudio con varias piezas - unas complementarias y otras "Compañeras" - de la camisa, como la almilla o armilla y las familias de cuellos (gorgueras, lechuguillas y valonas), que por falta de espacio no podemos exponer aquí. He tenido especial interés en recuperar el perfil de esta prenda y sus características formales, resaltando también el uso y las circunstancias que rodearon su "historia".

mujer, mantas o bancales, mantos, medios mantos, mantillas sereneros y mantillinas), medianeras (las prendas de lo que denominamos "estar a cuerpo") y hondoneras o bajeras, prendas interiores o remudo (en la mujer la camisa y las enaguas, y en el hombre el camisón, los calzoncillos, la almilla y las calcetas). Por eso se señalan las diferencias entre "estar vestido", "estar a cuerpo, "estar desnudo" (lo que hoy llamaríamos "ropa de faena"), y "estar en carnes" o "en cueros", in puribus. Atendiendo, finalmente, a las fábricas de que se componen las prendas tenemos las grandes familias de lino, lana, seda, algodón, mezcla y piel. 


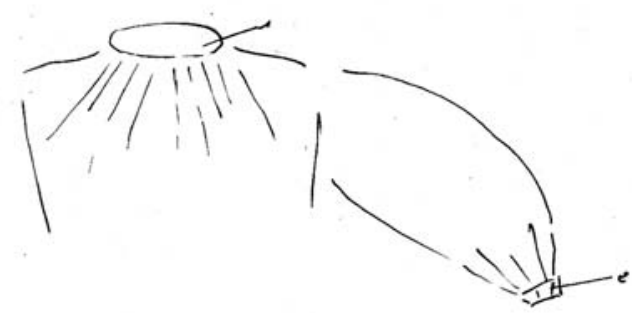

FIgURA 2.-Camisón o camisa masculina del siglo XVI: 1: cuellos; 2: puños. Dibujo A. Cea.

Solamente cuatro poblaciones serranas aportan documentación en el siglo XVI, a partir del año 1581: La Alberca con 4 ejemplos (dos de hombre y dos de mujer), San Martín del Castañar con 6 - aquí en un solo inventario y sin especificar género-, año 1599, San Miguel de Valero con 2 en 1581 y Sotoserrano con 27 testimonios (8 camisones o camisas de hombre, 4 camisas de mujer y el resto sin especificar). En total 39 ejemplos. En ninguna ocasión se facilita su precio y solo en Sotoserrano, su fábrica: 5 camisas de Guarda, 3 de lienzo común y una de frisa. Se mencionan como elementos los ruedos, los puños y los cuellos. En dos ocasiones y respecto a la guarnición se citan "camisones labrados de seda negra".

A pesar de la escasez documental conservada en este siglo (inventarios, testamentos y casamientos) extraemos de ellos unos resultados esclarecedores sobre su uso, circunstancias y tendencias. La camisa puede aparecer como pieza suelta, o formando parte de remudo. o como elemento del vestido completo o "cumplido de pies a cabeza": "botas, camisón, calzones, sayo, jubón, caperuza y por capote la mí capa". También como herencia de un vestido cotidiano de testador, como vestido "en palabra de casamiento" "cinco camisas medianas y su vestido de cada día, con lo qual el dicho Juan Horcajo puso su palabra de casar" ${ }^{3}$ ); en casamiento o en Vistas; "como su dueño lo gasta"; "así como yo lo traigo"; "Como parte de la mortaja" (Cea 1985b: 22-25); "Una camisa de mujer, buena de guarda y otra camisa que lle-

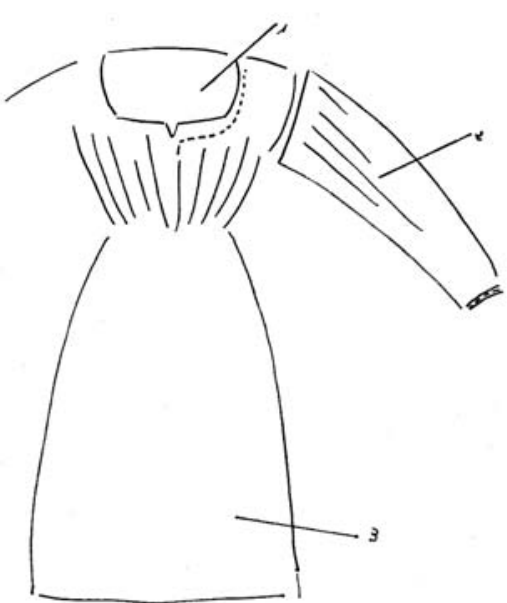

FIgura 3.-Camisa de mujer, siglo XVI: 1, cabezón; 2, mangas; 3 , rodo como parte baja del árbol. Las labores son en seda negra y colorada y en seda blanca y colorada. Dibujo A. Cea.

\footnotetext{
${ }^{3}$ Sotoserrano, año 1586, Casamiento de Juan Horcajo. AHPS. Prot, 6285, ff:175-175v. Dar y quitar o soltar palabra de casamiento son expresiones que aluden a la unión o disolución de una promesa. Esa palabra de casamiento tenía para los novios validez de cuasi documento y compromiso real, hasta el punto de que, desde ese momento, podían dar por establecido el matrimonio y el uso del matrimonio. Error que los visitadores eclesiásticos no cesaron de denostar en los llamados "Mandatos de Santa Visita", alertando de que no hubiera mucho tiempo entre la palabra dada y las propias velaciones o esponsales. Dar palabra era cosa de los dos contrayentes, en cambio quitarla o soltarla podía ser de uno de los dos, con los consiguientes pleitos que esto acarreaba.
} 
vo vestida". Está claro ya en este siglo que la camisa se confecciona en función de lo que está a la vista (los cuellos, cabezones, mangas y puños) y de lo que no se ve, de ahí las distintas calidades en cada parte. La camisa no es, pues, un todo enterizo sino que se compone de una serie de elementos acoplados, o sueltos, según la vida de cada prenda, en el momento en que se realiza el inventario: "un par de puños y un cuello de camisa; el cuello y los puños, casi nuevos".

El inventario por fallecimiento en 1587 de Antonio Pérez, "xastre" de Sotoserrano, es en mi opinión excepcional (y entrañable) porque nos hace partícipes de la paralización del taller a su muerte: "Varios camisones de ombre mediados; una mesa grande para cortar ropa; una saya con faldillas, buena; un sayuelo negro viejo; seis tocados de mujer: diez baras de lienço; un faxero colorado; una faxa de contray; una capa de contray; pedaçillos de contray para ribetes" (AHPS. Prot. 6285, f. 2 y ss.). En San Miguel de Valero, María Alonso deja en manda testamentaria de 1581 "a su hermana una saya y una camissa y un vello y un voço, y a su hija una faxa, una manta y una camissa" (APS. Miguel. Difuntos de 1572, f. 133).

Un inventario de San Martín del Castañar, año 1599, da pie a posibles interpretaciones. "Seis camisas de las nuevas, las dos [sic por "dos de ellas"] mui viejas". Interpreto "de las nuevas" como de hechura a la moda, y "muy viejas" en relación al mal trato o el excesivo uso en que se encontraban (APSMtn. Libro de Fábrica; inv., s.f.). Por contraposición tenemos la expresión "estar en pie", o "prenda que está en pie", entera y en buen uso (Sotoserrano, año 1595, documento de juicio matrimonial por separación de bienes. AHPS: Prot. 6287, f.84 y ss).

\section{EL SIGLO XVII}

Aportan información en este siglo las siguientes poblaciones: La Alberca con 25 ejemplos, entre los años 1685 y 1688; Cepeda, 187 (1640-1699); San Martín Del Castañar, 41 (1617-1690); Sequeros, 72 (1629-1699), Sotoserrano, 56 (1601-1699) y Zarzoso, 4 (1627). En total 385 casos documentados.

La eclosión de la camisa que ofrecen en estos años la villa de Cepeda y las otras cuatro poblaciones serranas no se corresponde como quisiéramos con una riqueza descriptiva de sus elementos y ornamentación que ayudara a perfilar, de manera más clara, su estudio. Podemos afirmar que en estos años se completan ya todos los términos o voces de que consta la camisa: cabezón o cabezones y cuello, mangas ("apuñetadas" o con sus puños), casi siempre de lienzo y olanda; árbol ruedo o rodos y falda o faldas; botones; nesgas, "Camisón de Ruán bueno con sus ñesgas a los lados", en inventario de Alonso Ramírez, noble, año 1655 (Prot. 5984 ff: 161 y ss.), como novedad en Cepeda y flecos o fluecos (1693). Es frecuente la presencia de piezas sueltas, especialmente los cabezones y la cuantificación de su precio (14 ejemplos en Sotoserrano).

Las fábricas fraccionan la calidad de la pieza en partes visibles y no visibles, con predominio del lienzo y sus variantes de Guarda y la Güebra, además de otras fábricas como la olanda, el ruán, los belos (en San Martín del Castañar) la palmilla y la lanilla, quedando relegada la estopa a las partes ocultas en los ejemplos más villanos.

Se mantiene moderadamente el uso de la seda negra como labor bordada, que comparte espacio a veces con la guarnición mechada o colchada (Cea 1895a: 174184; Id. 148-149). 


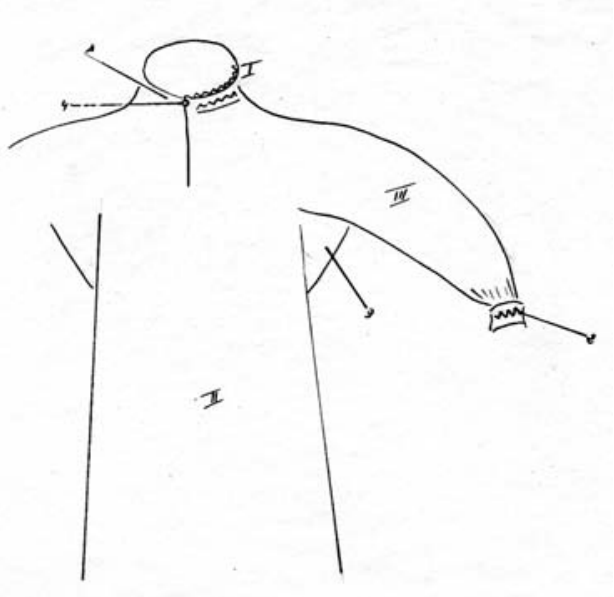

FIGURA 4.-Camisón del siglo XVII: I.- Cabezón. 1: cuello con puntas; botón, generalmente de plata. II.- Árbol, casi siempre de sedija, o estopa. III.- Mangas (no se detalla en este siglo su guarnición) 2: puños, llanos, o labrados; 3: nesgas. Dibujo A. Cea.

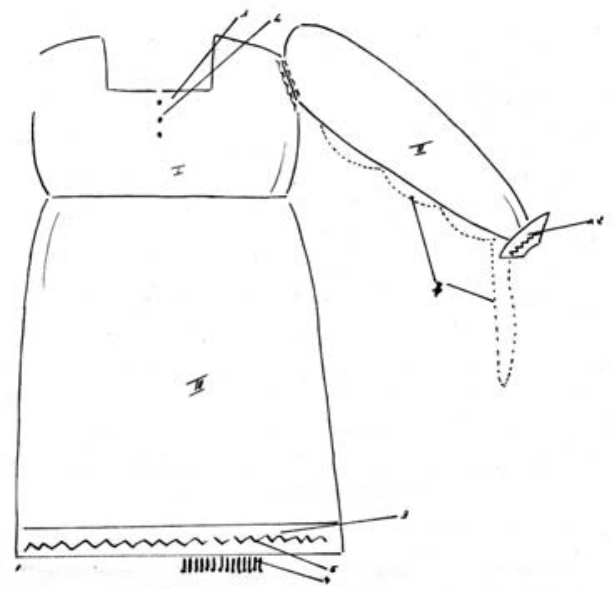

FIGURA 5.-Camisa de mujer, siglo XVII. I: Cuerpos, generalmente de lienzo, con los elementos siguientes: 1, cabezones o cabezón (suelen ir labrados de negro o de caparrosa y azul); 6, botones de metal (no se enumeran). II: mangas de lienzo y holanda; 2, puños (llanos o labrados con puntas); 7, puño con el corte "a uso de ciudadanas" (van señalados con trazos discontinuos). III: Faldas, a veces labradas o con fluecos; 3, rodo, ruedo o rodos, en ocasiones labrados con caparrosa; 4, fluecos de lanilla negra; 5, puntas. Dibujo A. Cea.

La villa de Cepeda ofrece la mayor cantidad y diversidad en el empleo de esta obra colchada (30 ejemplos) con las siguientes alternancias: sin especificar color; "colchada y labrada de açul y caparrosa" (13 veces); "colchada de blanco" (8); solo "labrada en azul" (4); y también "labrada de blanco", o la más tradicional: "labrada de lanilla negra". En un caso los rodos van obrados de caparrosa ${ }^{4}$.

A estas variaciones se añade en Sotoserrano la de la "lanilla colorada" y, como novedad, el "colchado con oropel" (en 2 ocasiones), modalidad que también se utiliza en Sequeros (2 inventarios), además del "labrado de cárdeno".

La villa de San Martín del Castañar parece marcar variante en la guarnición con 5 ejemplos de bordado en "hilo amarillo" y especialmente en la fórmula "redonda" del cabezón: "Camisa de mujer redonda, sin falda; el cuerpo de estopa y las mangas de lienço", año 1673. En este mismo inventario se mencionan: "dos camisas de mujer de lienço y mangas de olanda, cortadas al uso de ciudadanas, la una con botones de

\footnotetext{
${ }^{4}$ Existía la costumbre imitativa de copiar motivos decorativos, en unos casos tomados de otras prendas del propio ajuar de la casa y también motivos prestados, además de los modelos por dechado. En el año 1673, entre las prendas y alhajas nombradas en el inventario del noble, Francisco López, vecino de San Martín del Castañar, se menciona un "Dechado de muestras de cañamazo para labrar y sacar labores" (AHPS: Prot. 6190, ff:12 y ss.).
} 
plata" (inv. de Francisco López. AHPS. Prot. 6190; ff.: 12 y ss.). En inventario del Lcd ${ }^{\circ}$ Carrasco, clérigo, vezino de San Martín y cura en La Nava, año 1669, se describe una "Camisa de mujer labrada de amarillo, dijeron ser de Ana Espinosa"; prenda probablemente empeñada (AHPS. Prot. 6189; ff.: 100-101v).

Las poblaciones de San Martín y la Alberca tenían consolidado en el siglo XVII el uso de la camisa con botones de plata (al menos 3 ejemplos en camisones masculinos), poblaciones donde solo se menciona la fábrica de lienzo y el uso de las "puntas" como guarnición.

No aparecen especificadas las medidas de la camisa aunque están, en cambio, muy bien representados sus precios: en Cepeda, entre 10 reales el más bajo y 37 el más subido; en la Alberca, entre 11 y 40; en San Martín, entre 8 y 40; en Sequeros, "una camisa vieja de estopa se apreció en 3 reales". El resto de las poblaciones, entre 15 y 50 reales. Por último, Sotoserrano con una camisa valorada en 15 reales y dos colchadas con oropel que fueron tasadas en 28 y 50 reales respectivamente. Sí nos ofrece esta población varios costes de cabezones de camisas, en 6 maravedíes, y en 4 y 5 reales y medio, uno de ellos labrado de caparrosa alcanzó los 60 reales. En Sequeros varios cabezones oscilaron entre 5 y 10 reales.

En cuanto al número de camisas por inventario, recogemos 7 ejemplares de mujer en Cepeda, 6 en San Martín, 11 en un mismo inventario de Sotoserrano y el desbordante número de 34 camisas en un solo ajuar de Cepeda, 13 de ellas con labores colchadas.

Resaltamos como curiosidad en este siglo el inicio del uso de colores no exclusivamente blancos. En el testamento de Santiago Soria, vecino de Sequeros, año 1654, se deja a una "María Peral, una camisa negra de Palmilla. Además, una camisa colchada de blanco y otra de caparrosa, una de negro labrada, más tres de blanco" (AHPS. Prot. 6224, sf.). Se distingue aquí entre "obra labrada" y "obra bordada" (González 1944). En el año 1679 en San Martín del Castañar se nos ofrece la instantánea de un caso de pentimento en el momento en que el tasador, al "cantar" al escribano la labor de la camisa que se estaba inventariando, rectifica el término ajustando literalmente el tipo de labor del que se trata: "Camisa de mujer bordada, digo labrada, de lanilla negra sin ruedo" (AHPS. Prot. 6191, ff: 23 y ss.) [la negrita es mía].

En el año 1683 se describe en Sotoserrano «una camisa negra sin ruedo en 15 reales, más una camisa colchada de oropel en 28" (AHPS. Prot. 6303, f.262v). Hay otros tres ejemplos en Cepeda, el primero de ellos en la dote de Pedro Blanco y María Gutiérrez, año 1667: "Tres camisas de mujer labradas de seda negra 30 reales, más tres camisas de mujer colchadas de blanco, 84 reales" (AHPS.Prot. 5987, ff: 88-90v); “Una camisa negra nueva y dos llanas" en inventario de María Conde, viuda, año 1686 (AHPS. Prot. 5992, ff: 91 y ss.). Por último, en una dote del año 1693: "camisa de lanilla negra con faldas, en 22 reales" (AHPS.Prot. 5993, ff: 170-173).

Aparece como novedad el empleo de la voz "camisa" formando parte del traje de disciplinante $^{5}$ (Cea 1985: 22-25). En la partición de bienes de Mateo García, vecino

\footnotetext{
${ }^{5}$ El traje de disciplina y por tanto la camisa se empleaba no solo en las procesiones de penitencia y en el ritual del Lavatorio de los pies, las colaciones y los oficios del jueves y viernes santo, sino también como posible mortaja, además del tan frecuente hábito de San Francisco o el de otras religiones.
} 
de Cepeda, año 1642, se menciona "una camisa de disciplina, valorada en 500 maravedíes" (AHPS. Prot. 5981, ff: 188-211). Cuatro ejemplares más figuran en Sequeros, entre los años 1697 y 1699, detallando los elementos que componen ese traje: 1697, "Camisa de disciplina con su capillo y cordón de monjas" (Inv. M ${ }^{a}$ Rodríguez de Domingo Anaya. Prot. 6234, f.137v); 1698, "una camisa de disziplina con su capillo" (Inv. Jazinto Garzía. Prot. 6234, f.285v); 1699, "una camisa de disziplina con su capillo" (Inv. Antonio Anaya. AHPS. Prot. 6235, f.151); 1699, "una camisa de disciplina con su ramal" (Inv. Antonio Anaya. AHPS. Prot. 6235, f.151).

En Sequeros con fecha de 23 de enero de 1638 y por escritura de contrato entre Lorenço de Anaya, vecino de ese lugar y Francisco Martín Moço, del de Casas del Conde, se ofrece la costumbre de canje por compra en el servicio al rey (sustituyendo el mozo pobre al mozo acomodado) y las condiciones del contrato, en cuya soldada entran camisas y valona como su complemento: "que dicho Francisco á de ir por dicho Lorenço, es soldado listado [...], y el dicho Lorenço Anaya le á de dar adicho Francisco Moço 180 reales de buena moneda corriente y un vestido y espada y daga, y el vestido á de ser de paño de hasta siete u ocho reales la bara, que será: capote, ropilla y balón, medias y çapatos y sombrero y dos camisas y una valona y esto se le á de dar a el tiempo que arrancare para la guerra o a donde su majestad le mandare y esto se entiende si admitiere por soldado" (AHPS. Prot. 6235, ff. 96 y ss.) 6 . Por último, queremos resaltar la intención y la causa — personal, circunstancial o vital- por la que una prenda, aquí la camisa o el camisón, pasa en testamento a nuevo dueño (parientes, criados, o pobres) bajo las siguientes fórmulas: "porque me encomiende a Dios", "porque bien me sirvió", "porque lleve mis ofrendas" ". En cada ejemplo se particularizan, igualmente, la calidad y estado de lo que se deja en manda: camisas y camisones "buenos", "nuevos", "comunes", "traídos", algo servidos", "viexos" y también los de "por hazer" (en este caso se fija el precio que ha de gastarse en su hechura). Asimismo, el heredero recibe la información pormenorizada del uso y estima de lo que su amo le da en herencia: "una camisa de las mías", "del vestir", "de las que [yo] tuviere"; "formando parte del remudo"; "del vestido cotidiano" o "de su diario vestido"; "del hato y vestido de cada día"; "de las mejores que tengo"; "que tiene reservado para los día festivos", "pazido de polilla bastante". Estaba, además, el "hato cadaniego" de los amos a los criados con todas sus derechuras. En el año 1627 "la Señora Abadesa [de Zarzoso] dio 4 camisas de lienço y estopa a las dos moças de casa, el año que les dio sus derechuras" (AHN. Sección Clero, Libros: 11153. Cuentas de 1627, f. 15v).

\footnotetext{
${ }^{6}$ Esta costumbre aún estaba en la memoria, en los años 70 del pasado siglo, entre algunos de mis informantes serranos, que habían hecho el servicio militar bajo esta modalidad.

7 Estas herencias, generalmente prendas de vestir del testador, se repartían primero entre parientes (desde los de vínculo de sangre más directo a los más lejanos), y luego entre criados y servidores, vecinos y amigos por razones de cariño o en pago de diversos servicios, prestados o por prestar, especialmente en el caso de la llamada "mujer de las novenas", encargada de llevar las ofrendas establecidas según costumbre y por testamento en las misas y honras de difuntos durante el tiempo y forma acordados. Generalmente, la prenda que se daba en manda debía estar acorde en calidad y estado con la deuda u obligación establecida entre oferente y testador.
} 


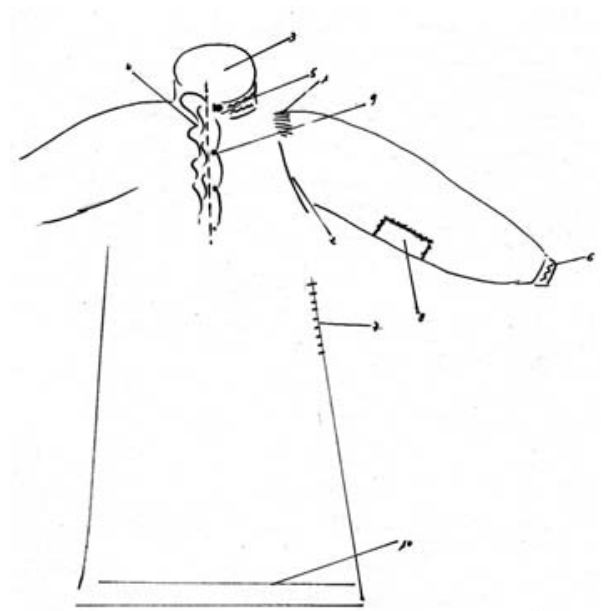

FIGURA 6.-Camisón, siglo XVIII: 1, hombreras; 2 , sobacos; 3 , cuello (con o sin puntas); 4, paperas (propio de la moda "a uso de ciudadanos"); 5, collar; 6, puños, con puntas y otras labores; 7, costura "de puntada"; 8, asiento o remiendo; 9, botones de metal, plata, otros (la variante de vistas admite botonaduras de entre 6 y 8 botones); 10 , ruedo o rodo. Dibujo A. Cea.

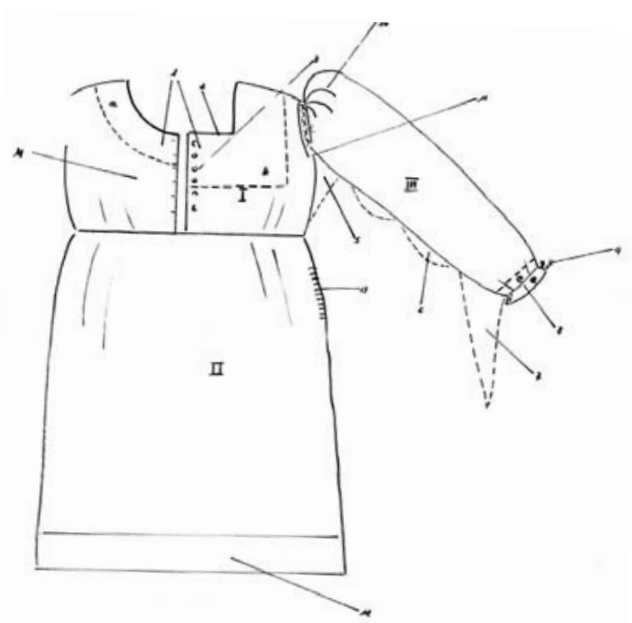

FigurA 7.-Camisa de mujer, siglo XVIII: I. Cuerpos con los elementos siguientes: 1 ; porteras $\mathrm{O}$ puertas; 2, cuellos: a) redondos; b) cuadrados; 3 , botones, de metal, llanos o labrados (entre uno y seis); 4, pechos (suelen adornarse con motivos de ramos y cuecos); 5, ayre/aire (señalado con trazos discontinuos). II. Faldas o árbol: 12, ruedo (con una medida de tres cuartas); 13, puntada o costura. III. Mangas: 7 , bocadillos (probable elemento exclusivo de la variante "a uso de ciudadanas"); 7, mangada/mangaxa/mangaxos; 8 , puños: a) llanos; b) labrados; c) con puntas; 9, botones y ojales/ aujales. Van bordados con lana de borrega de colores negro, azul, yema de huevo y encarnado; 10, hombreras, labradas de negro y blanco y listoncillo encarnado y verde; 11, sobacos. Dibujo A. Cea.

\section{LA CAMISA EN EL SIGLO XVIII}

Son 12 las poblaciones serranas que en este siglo aportan documentación sobre la camisa, más Candelario en la Sierra de Béjar: La Alberca, 41 ejemplos; Arroyomuerto, 2; Candelario, 149; Casas del Conde, 14; Cepeda, 480; Cereceda, 2; Garcibuey, 3; Miranda del Castañar, 13; Monforte de la Sierra, 20; San Martín del Castañar, 7; Sequeros, 31; Sotoserrano, $16 \mathrm{y}$, finalmente, Villanueva del Conde, 54, que suman un total de ¡832 ejemplos sobre la camisa! .

\section{Elementos de la camisa que se especifican en los documentos}

- Árbol: "Un árbol de una camisa de lienzo viejo”, año 1794. San Martín del Castañar (Inv. de Ana Alonso. AHPS. Prot. 6199, ff: 62-65).

\footnotetext{
${ }^{8}$ Tenemos también los valores parciales donde se diferencia la camisa de mujer y la de hombre o camisón, que eludo para no sobrecargar este trabajo de adherencias cuantitativas.
} 
- Asiento (se utiliza como sinónimo de remiendo): "camisón con un asiento que se le ha echado al cuello", 1789. Candelario (Inv. de Juan Bejarano (AHPS. Prot. 1142, ff: 7 y ss.); en 1796, "un camisón remendado con asiento, 20 reales" (Inv. Ana Gonzáles Rico (AHPS.Prot. 1142, f.10). Se conservan cinco ejemplos en Candelario entre los años 1779 y 1789.

- Ayre: «una camisita de mujer con ayre, 20 reales",1794 .Villanueva del Conde (Inv. De Agustín Sánchez Cerezo. AHPS. Prot. 6332, f.45).

- Botones: En Monforte de la Sierra se menciona sin más un juego de botones; 3 en Las Casas del Conde; 6, correspondientes a una camisa de mujer en Sotoserrano. En Villanueva "camisón con dos pares de botones de plata del camisón", año 1765 (Inventario. AHPS. Prot. 6320, ff: 4 y ss.) En Cepeda, año 1785, "camisón con dos botones de plata aumados y dos piedras" (Inv. Lino Sánchez Montero, provisor síndico general. AHPS.Prot.6014, ff: 167 y ss.). Los botones de plata suelen ir asociados a camisones de Vistas.

- Collar: "un camisón antiguo con collar de maragato" en la Alberca, año 1733 (Inv. Theresa González. AHPS. Prot. 6103, ff.80-81)9.

- Cuadrados: cuartos delanteros y cuartos traseros. Solamente se documentan en Villanueva y Cepeda.

- Cuello: "dos camisas sin faldas y son de cuello redondo". Se cita este término una vez en Cepeda, año 1757, en inventario de Ambrosio Pérez (AHPS. Prot. 6006, sf.).

- Cuerpos: Toda la parte superior de la camisa, se registra una vez en Villanueva.

- Encorporadas: "dos camisas encorporadas sin ruedo", año 1775, esto es, con las mangas cosidas al cuerpo. Aparece en documento de Garcibuey (AHPS. Prot. 6150, f.199v).

- Falda y Faldas de camisa/Faldones/Faldetas: 3 ejemplos en Sequeros; 3 en Candelario; 4 en Sotoserrano y 63 en Cepeda. Al contrario, su carencia se hace notar en Miranda del Castañar: "Una camisa sin faldas".

- Labrada/Labradura: sic por bordada, en este caso en referencia a las hombreras de camisa o de camisón candelarios, generalmente con lana negra sobre el lienzo de la camisa, y en 1778, en el inventario de la viuda y herederos de Pedro Barruelo, "labrada de ilo blanco, 20 reales" (AHPS.Prot.1140, ff.ss.).

- Listoncillo: elemento y guarnición en las camisas candelarias con hombreras: "camisa de ombrera blanca con listoncillo encarnado sin faldas, 16 rs.", en 1767 (Inv. Francisco Bejarano. AHPS. Prot. 1138, f.3.); en 1783, "camisa de hombreras blancas nueva con listoncillo verde y encarnado en ella y faldas, 44 reales" (partición de Ana García. AHPS. Prot. 1141, 29 folios); "camisa de ombreras blancas con listoncillo en ellas, 16 reales", 1794 (inv. Pedro Martín de Navacarros y Margarita Sánchez Vaquero, AHPS. Prot. 1142, f.9v.).

\footnotetext{
${ }^{9}$ Este texto sobre el camisón de maragato o con collar de maragato puede aludir a una variante arcaizante y según la manera de esa comarca leonesa, si tenemos en cuenta otras prendas antiguas que se citan en ese mismo inventario albercano, como "una valona antigua, una faja antigua, una camisa labrada de negro mui antigua, un tocado de cuerno y dos camisas antiguas de mujer. Parece menos probable que se refiriera a un tipo de camisón para época de carnaval que vistieran los seis matrimonios llamados "escancianos", casados en ese año. También se llama aquí "maragatos" a un tipo de arreos muy vistosos con que adornan este grupo sus caballerías para pasear en esos días de fiesta por las calles albercanas (Vid. Lorenzo-Sánchez 2006: 132).
} 
- Mangada. En 5 documentos de Cepeda se cita "una camisa mangada" y una sola vez en Candelario y en Las Casas del Conde, en testamento de 1760 (AHPS. Prot. 5976, ff: 11 y ss).

- Mangajo y Mangajos: Aparece 7 veces esta denominación como fórmula alternativa de las camisas conocidas como "de ala perdida", con distintas guarniciones: de seda negra, colchada, antigua, de hilo azul y de pita colorada; variantes que se conservan fosilizadas como prendas-testigo en ejemplos de imágenes vestideras serranas.

- Mangas: 1 ejemplo en Villanueva, año 1765 (AHPS. Prot. 6320, f.3).

- Mangas de aguja: Se mencionan en un inventario en Cepeda, año 1708.

- Ombrera/Hombreras o de Ombreras: Este elemento está presente en 25 documentos, siempre como variante de Candelario, el primero de ellos en el año 1712 y el último en 1796. Se enumeran ombreras sin especificar y también ombreras blancas, ombreras de dos hilos, ombreras blancas con listoncillo en ellas y sobre todo un "Camisón de Vistas con hombreras, tasado en 40 reales", año 1796, en el inventario de Ana González Rico (AHPS. Prot. 1142, f.9).

- Papos y Papera: En Villanueva del Conde, año 1780, está presente esta fórmula en inventario de María Alonso: "Camisón bueno labrado con papera de Baynica y votones de plata” (AHPS.Prot. 6324, ff: 161-163).En ese año y villa, se describe, en inventario de Ángela Martín un "camisón nuevo vordado con vainica y puntas de la boda; otro, nuevo, el día de los pregones" (AHPS,Prot. 6324,ff: 203-206). En la misma localidad y año 1791, «un camisón nuevo con papera en 31 reales» (Inv. Manuela Álbarez. AHPS. Prot. 6327, ff: 133-137v).

- Pecho de: Una "Camisa de pecho con Ramos y ombreras de lana negra sin faldas" es descrita en Candelario, año 1720, en el inventario de Joseph Hernández García Rico (AHPS.Prot. 1134, ff: 20 y ss.).

- Porteras o Puertas: "Unas mangas y unas puertas de una camisa de lienzo", inventario de Villanueva, 1765 (AHPS. Prot. 6320, f.3).

- Puños: En el inventario de Margarita Mateos, vecina de Candelario, año 1795 , se halló "una camisa de ombreras, terilla y puños de lana negra, sin faldas 6 reales" (AHPS. Prot.1142, 25 folios).

- Ramos: De nuevo en Candelario y entre los bienes de Joseph Hernández y García Rico aparece descrita en 1720 esta ornamentación fitomorfa: una "camisa de pecho con Ramos y ombreras de lana negra sin faldas en 14 reales" (AHPS. Prot. 1134, ff: 20 y ss.). En Villanueva del Conde, año 1790: “Camisa con muchos ramos, 53 reales" en el de Agustín Martín Cortes (AHPS. Prot. 6326, ff: 721); en 1973, "Camisa nueva de Ramo estrenada", en inventario de Rita Marcos (AHPS. Prot. 6328, f: 48). También en la tasación de bienes de Manuel Sánchez del Cerezo, 1794: "camisa nueva sin ruedo y con ramos, 30 reales" (AHPS. Prot. 6328, ff: 191 y ss.).

- Remiendo/Remendón: En el año 1784 figuran en el inventario de Santiago Martín Barruelo "dos camisones remendones buenos, 22 reales" (AHPS. Prot. 1141, ff: 42 y ss.).

- Rodo/Ruedo/Ruedos: 7 ejemplares "del uso de la niña" se citan en Villanueva, año 1780 (AHPS. Prot. 6324, f.293-206), y "Dos camisas encorporadas sin ruedos» en Garcibuey (Inv. Ana Andrés. AHPS. Prot. 6150, f.217). También, 2 ejem- 
plos en Miranda, 5 en Sequeros, 9 en Cepeda y 10 en Candelario, uno de ellos, en el año 1768, con sus medidas: "Siete quartas de cerristopa para el ruedo, 7 rs."; (Testamento de Ana Hernández Rico. AHPS. Prot. 1139, fs.). En Casas del Conde se repite de nuevo la misma medida, en testamento de 1772, "siete quartas de estopa para el rrodo de una camisa" (AHPS. Prot. 5976, ff: 76 y ss).

- Sovaco/Sobaco: En inventario candelario de Juan Bejarano, año 1789 se halló un camisón con asiento nuevo, [y] otro con asiento más usado y con remiendos, [en] siete. Un camisón con asiento y rroto por las mangas y el sovaco, 5 reales y medio" (AHPS. Prot. 1142, ff. 7 y ss.).

- Terilla: En Candelario esta voz alterna como guarnición y es sinónimo de listoncillo en el testamento de Margarita Mateos, año 1795: "Camisón de ombreras, terilla y puños de lana negra, sin faldas, 6 reales." (AHPS. Prot. 1142, 25 fols.).

La Alberca, con 10 documentos, es el máximo exponente de la camisa conocida como "de Desposados", 4 de ellas con su botonadura de 5, 7 y hasta 9 botones de plata, en uno de los casos con labor de filigrana; 3 van en un camisón sin especificar materiales y en otro caso 6 botones más y "un botón de plata en camisa negra".

\section{Fábricas de las camisas en el siglo XVIII}

- Lienzo. 47 documentos describen las camisas como de lienzo sin especificar calidad ni fábrica: 1 ejemplo en la Alberca; 6 en Candelario; 1 en las Casas del Conde; 27 en Cepeda; 1 en Monforte de la Sierra; 4 en San Martín del Castañar; 2 en Sequeros; 1 en Sotoserrano y 4 en Villanueva del Conde.

- Guarda. Procedentes de esa ciudad portuguesa o con esa calidad hay 5 ejemplos: 4 en Candelario y 1 en Cepeda (Virgilio Bejarano 1950: 243-263 y Giese 1955: 3-14).

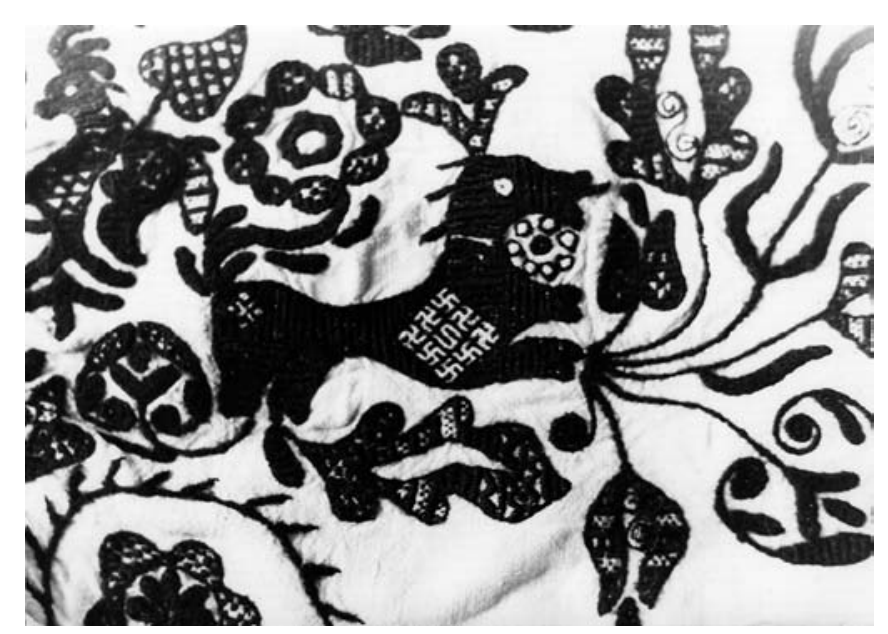

FiguRa 8.-Camisa galana. Detalle de la guarnición de las mangas con motivos de león pasante y tenante coronado y esvásticas en el corazón mientras sostiene un ramo + pájara o cueca recelosa con ramo de hojas cordiadas y otros motivos fitomorfos (Alberca, col. Part.). Fotografía A. Cea. 
- Bocadillo: 1 en Candelario (Serrera 1974: 47).

- Cerristopa/Zerristopa / Estopa. Esta clase de lino, basta y ordinaria, es empleada 10 veces, generalmente en las partes no visibles de la camisa como el ruedo: 3 en ejemplos de Candelario; 2 en Cepeda y Sequeros respectivamente y una sola vez en Alberca, Miranda y Villanueva (Cea 1982: 161-198).

- Seda. 4 ejemplos: 3 en Candelario y el otro en San Martín.

- Ruan y ruan de seda. 6 inventarios, 5 en Candelario y 1 en Cepeda.

- Hilo sin especificar: un solo documento en la Alberca.

- Hilo de pita: 1 en Candelario.

- Lana negra: 1 en Cepeda y 1 en Sotoserrano.

- Plumas reales: 1 ejemplo en Casas del Conde, año 1782.

\section{La guarnición: técnicas, motivos y colores}

Aparecen mencionados en este siglo y como novedad los motivos de "ramos", "ramos y cuecos" o "pájaras", con 9 ejemplos en Villanueva del Conde y 3 en Candelario:

- "Camisa colchada de lana negra sin faldas y con rramos" (Candelario, 1710, inventario. AHPS.Prot.133, f.4v).

— "camisa de pecho con rramos y faldas, en 26 reales" (Candelario, 1738, Inventario de Santiago Rico, AHPS. Prot. 1135, f.30).

- "camisa labrada de negro con ramos y cuecos, nueva" (Villanueva, 1769, inventario. AHPS. Prot. 6321, f.11 y ss.).

- "camisón labrado de negro con ramos y ruedo" (Villanueva, 1780, inventario de María Alonso. AHPS. Prot. 6324, ff: 161-163).

- "camisa labrada de negro, mediada, de la muchacha con sus rramos"; parece ya un motivo habitual en esta población (Villanueva, 1781, inventario de Marivela Martín, AHPS. Prot.6324, ff: 32-35v).

— "camisa con muchos ramos, en 53 reales" ${ }^{10}$ (Villanueva, 1790, inventario de Agustín Martín Cortes, AHPS: Prot.6326, ff: 7-21).

- "Camisa nueva de Ramos"; se ve aquí ya como variante consolidada (Villanueva, 1793, inventario de Rita Marcos, AHPS. Prot. 6328, f.148).

- "camisa nueva sin ruedo y con ramos, en 30 reales" (Villanueva, 1794, inventario de Manuel Sánchez Cerezo, AHPS. Prot.6328, ff: 191 y ss.).

Se mantiene en este siglo el gusto por las labores en lana y seda:

- 59 ejemplos en que se emplea lana y lanilla negra: 17 en Cepeda; 14 en Sotoserrano; 11 en Sequeros; 5 en Las Casas del Conde y Villanueva respectivamente; 3 en Sotoserrano y 2 en la Alberca y en Miranda.

- 16 camisas labradas en lana azul: 6 en Cepeda; 5 en la Alberca; 2 en la Alberca y en Candelario respectivamente y 1 en Villanueva.

- 10, en azul y caparrosa: 6 de ellas en Cepeda y 4 en la Alberca.

\footnotetext{
${ }^{10}$ Parece generalizada en Villanueva del Conde la tendencia a recargar la ornamentación, aquí de las camisas y camisones, inclinación que ya pudimos comprobar para el caso de las cobijas o ventiosenos en San Martín del Castañar (Cea 1985b: 67) sobre el resto de las poblaciones serranas.
} 


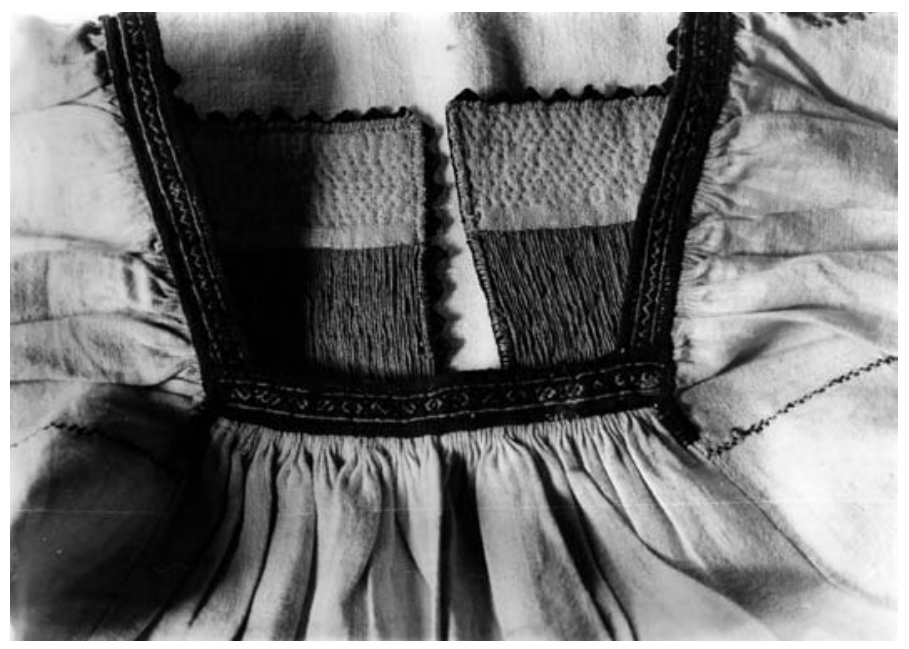

Figura 9.-Camisa de mujer, detalle del cabezón y porteras. La fábrica es de lienzo del país con labores de caireles y ramos en lana de borrega. Por el reverso los pliegues van ayudados a mantener su forma endurecidos con aguamiel (Alberca, col. Part.). Foto A. Cea.

- 20 ejemplos de camisas labradas en caparrosa o cárdeno: 7 en Cepeda; 6 en Monforte y una en las poblaciones de Arroyomuerto, Garcibuey, Miranda, Monforte, Sequeros, Sotoserrano y Villanueva.

- 7 camisas bordadas en hilo blanco: 5 en Cepeda y 1 en Candelario y San Martín respectivamente.

- 8 bordadas en seda y seda y lanilla blanca: 6 de ellas en Cepeda y 1 en Candelario y Sotoserrano.

- 1 ejemplo en San Martín del Castañar, en 1701, de bordado amarillo, probablemente lana, color que caracteriza las camisas en esa villa serrana. No se conserva, que sepamos, ninguna pieza-testigo de estas características.

La efectista y minuciosa labor colchada como guarnición en la camisa ${ }^{11}$, especialmente en las mangas, se ve representada en este siglo con 33 ejemplos en las poblaciones de Candelario, Cepeda y Villanueva del Conde. En 6 documentos no se expresan color, ni materiales. En 18 inventarios candelarios la guarnición de la camisa va "colchada de lana" o "colchada de lana negra y [formando] ramos"; 2 veces en esa misma población se muestra la variante "colchada blanca", otra, "colchada de seda negra" y una tercera, "colchada de hilo de pita". Finalmente en Cepeda, 4 camisas constan como "colchadas de labores" sin especificar sus figuras.

La guarnición de puntas, se supone que como labor en el cabezón y en los puños, está presente en este siglo en 19 documentos de camisas de mujer y de hombre en las

${ }^{11}$ Técnica que consiste en embutir algodón o seda entre dos telas que se cosen formando diversos dibujos (vid. s.v. Autoridades). La única prenda-testigo serrana que recuerde con esta técnica es una colcha de motivos geométricos que conservan las monjas franciscas del monasterio de Zarzoso. 
siguientes poblaciones: en Cepeda 7 veces, seis de ellas pertenecientes a un mismo ajuar: "Seis camisones apuntados de lienzo"; 4 en Candelario, una de ellas con las puntas blancas; 6 piezas en Villanueva, de las que 4 eran de hechura masculina o camisones; 1 en la Alberca y otra "camisa con puntas a los puños" en San Martín del Castañar.

La labor de vainica adorna dos variantes de hombre en Villanueva, inventario de Joseph Ximénez, año 1780: "camisón de caparrosa y votones de plata" y "camisón bordado, vaynica y puntas de [los llamados] de boda, otro nuevo del día de los pregones" (AHPS. Prot. 6324. ff: 203-206v).

La labor conocida como "de tirilla y listoncillo" figura en 8 camisas de hombre y de mujer en Candelario con listoncillos de seda, sin especificar color, con listoncillo encarnado y con listoncillo verde y encarnado, más otra "de terilla blanca, en este caso en camisa de mujer y "una camisa con la tira de negro" en San Martín del Castañar, año 1704 (AHPS. Prot. 6195, ff: 16 y ss.).

El uso de los colores en las camisas, las medidas, los precios y el número de piezas por inventario

En el siglo XVIII aumenta el uso del color negro en las camisas —en 15 ocasiones las camisas son negras y con labraduras igualmente negras-: 8 de ellas en Cepeda (años 1700, 1703, 1704-1705, 1708, 1710 y 1781; 2 en camisones de Cereceda, año 1780, y otros 2 en Miranda, en 1711 y 1753; 1 en Monforte, año 1766, 1 en Sequeros, en 1741, y otro en Sotoserrano "de los de la muchacha", año 1721.

De color azul: 3 casos, 2 en Cepeda, año 1701, "camisa de lanilla açul" y "camisa vieja açul labrada", y 1 en Miranda, año 1711, "una camisa labrada negra y otra azul".

De amarillo, 1 en San Martín del Castañar, en 1701. El uso del color en las camisas debió de empezar a ser tan generalizado que cuando en varias ocasiones se utiliza el color blanco se especifican como si esa alternativa fuera algo raro o inusual.

En el inventario de Ana Barrio, vecina de Cepeda, año 1705, se describe "Una camisa de caparrosa de mujer y otra de cárdeno de muchacha".

Se aportan las medidas de la camisa en la villa de Cepeda: "Una camisa y si no [la hubiese que se compren] dos baras y media de lienço para ella", año 1702. También, la del rodo con siete cuartas en Casas del Conde, año 1772. En dos inventarios se especifican las medidas de un remudo (compuesto de camisa, almilla y calzoncillos) en 5 varas.

Los precios en que son valorados las camisas y camisones van como sigue: entre 30 y 40 reales en las Casas del Conde; en Candelario los precios de las camisas y los camisones de hombre oscilan entre los 10 y los 41 reales (en 3 reales se apreció también "un camisoncito de niño"); entre 14 y 20 en Cepeda ( 5 reales se pagaron "unas mangas de mujer con sus puños"); en Miranda del Castañar, 27 reales por una camisa; en la Alberca entre 18 y 42 reales, una de ellas "de desposados"; en Monforte se tasó una camisa en 83 reales; en Sequeros, entre 15 reales y 48 por una "de boda" y 3 por un "camisoncito"; en Sotoserrano, 5 reales las más baratas, y 45 las de precio más subido, entre estas una camisa de lienzo y seda; finalmente en Villanueva, entre 9 y 28 reales las camisas comunes, entre 40 y 50 las buenas y entre 53 y 60 reales las llamadas "de boda".

Un ajuar o inventario generoso podía llegar a las 6 camisas (Monforte) y hasta 6 remudos (La Alberca). Entre todos los ajuares serranos sin duda el más opulento corres- 
ponde al inventario de Francisco Gascón en Cepeda, año 1704, con 33 piezas: "20 camisones, 7 camisas de mujer y las 6 restantes sin determinar género" (AHPS. Prot. 5997, ff: 200-211).

\section{Las hechuras inconclusas}

Los más que suficientes ejemplos que mostramos a continuación, casi todos ellos en documentos correspondientes a las poblaciones de Cepeda y Candelario, refieren a camisas inconclusas y muestran en instantánea el taller y cómo quedó cercenado por la guadaña de la muerte lo que se estaba componiendo por sastres y costureras.

- "2 varas y media de lienzo que está curado para hacer una camisa en casa de la costurera". Cepeda.

- "Dos camisas con sus faldones y hechuras". Cepeda.

— "la hechura de unos cabezones, 2 reales". Cepeda.

- "una camisa de mujer comenzada a hacer". Cepeda.

— "un camisón sin mangas, a medio hacer". Cepeda.

- "Una camisa nueva que está en casa de la costurera". Cepeda.

- "El paño que está cortado de sastre para hacerse de vestir". Cepeda.

- "echura de un camisón, 2 reales y medio". Cepeda.

- "echura y forro de una enguarina, 11 reales". Cepeda.

— "Una camisa dada la puntada”. Monforte de la Sierra ¿sic por hilvanada?.

- "Camisa de mujer cortada, en un emboltorio". Cepeda.

— "Una camisa que tengo en corte, sin quadrado". Cepeda.

- "tres porteras de camisa de mujer por hacer". Cepeda.

- "Camisa por hacer con la caparrosa y lo demás, 14 reales". Cepeda.

— "El ruedo que está preparado para la camisa, 7 reales". Candelario.

- "Un lienzo para que hagan camisas a mis hixas y un az de lino para que hagan los ruedos". Cepeda.

- "Camisa con el ruedo sin pegar [sic]. Candelario.

— "dos mangas de camisa de mujer cortadas". Cepeda.

— "el remudo todo con sus hechuras, 50 reales de vellón". Sotoserrano.

— "dos camisas de mujer cortadas". Cepeda.

— "la hechura de dos camisas con su hilo". Candelario.

- "en una pieza, camisa de caparrosa de mujer". ¿Por pieza hay que entender aquí la tela enteriza sin cortar aún, o la estancia en que se encontraba cuando se realizó este inventario? Cepeda.

- "A mi hermana, un rollo de lienzo para remudo de sus ropas blancas". Candelario.

— "Un corte de camisa de lienzo para el muchacho". Cepeda.

— "Tres camisas de mujer cortadas, sin falda". Cepeda.

- "Una camisa de mujer, lavrada en lana negra por acabar, en 38 reales". Garcibuey. 1806 (inventario de Miguel Paián ante el escribano de Miranda. AHPS. Prot. 6913, f. 165).

\section{Las ocasiones y las expresiones de uso}

En las siguientes ejemplos se determinan los diversos usos y fórmulas que por su calidad y estado se asignan en cada caso a las ropas destinadas al calendario diario y al fes- 
tivo atendiendo a su calidad y estado de conservación. También en relación a las edades de la vida, especialmente a las pautas establecidas para el noviazgo y la boda:

— "De su diario vestido"; "de mi vestir"; "de mi común vestir"; "a cada día"; "el hato de cada día"; "del uso".

— "La ropa que en los días ordinarios y feriados usa"; "la ropa, tanto diaria, como de días festivos".

— "El vestido dominguero".

— "Para los días festivos"; "de vestir"; "reservado para los días festivos"; "de gala" o "de galas"; "El vestido de excusa de mi hijo quiere que se tase al tiempo que se haga inventario" ${ }^{12}$. Casas del Conde.

— "La ropa del uso de los mozos" "13; "El remudo de novio"; "de vistas"; "de desposados"; "del día de la boda"; "cuando contraje matrimonio".

\section{Tendencias de la moda y variantes}

Las fórmulas y dichos que presentamos a continuación sobre las tendencias de la moda (arcaizantes, o innovadoras) son indicadores del gusto y la educación personal, la mentalidad, la imposición de la clase social, y el propio estatus:

— "Un camisón de los que se estilan gastar"; "del uso"; " del uso antiguo"; "que se estila en este lugar"; "según la común práctica y estilo de este Pueblo"; "al estilo de la tierra"; "al estilo del país"; "un camisón de muchacho de ciudad"; "un camisón de los de Madrid"; "de roquete» [¿sic por rizados?] (Sotoserrano, 1785); "de cuello redondo"; "de cuello de maragato".

\section{El estado de conservación de la pieza}

Las diversas expresiones establecidas sobre el estado de la prenda en el momento en que está siendo inventariada, que aquí reproducimos, manifiestan no solo la situación en frío y real de lo que se justiprecia, en esta caso el valor de la camisa por su conservación, también las subliminales apreciaciones externas y el juicio sobre el cuidado y la hacendosidad o el descuido personal y familiar de quien la vistió:

— "Sin estrenar"; "estrenada"; "nueva"; "en pie»; "mejor que mediada"; "mediada"; "algo servida"; "traída"; "muy traída"; "Vieja"; "Sucia"; "rota"; "remendada"; "Camisa pazida de la polilla bastante".

\footnotetext{
12 ¿Que se da a escondidas y sin figurar en inventario alguno?

${ }^{13}$ Puede entenderse como prendas domingueras, en este caso de mocedad masculina y también la ropa anual establecida junto a la soldada a los criados cuando entraban "a servir amo". Ataduras que se establecían anualmente por San Juan de junio.
} 


\section{LA CAMISA EN EL SIGLO XIX}

14 poblaciones conservan datos sobre la camisa en este siglo, con un total de 320 documentos: La Alberca, 8 documentos, entre 1802 y 1804; Candelario, 168 ejemplos (1802-1873); Casas del Conde, 3 (1800-1830); Cepeda, 69 (1805-1851); Cereceda, 1 (1806); Garcibuey, 2 (1803-1806); Madroñal, 1 (1821); Miranda del Castañar, 8 (18011858); Mogarraz, 2 (1864); Monforte de la Sierra, 10 (1809-1856); Pinedas, 1 (1833); San Martín del Castañar, 8 (1804-1859); Sotoserrano, 23 (1838-1857); Villanueva del Conde, $17(1800-1835)^{14}$.

\section{La Alberca}

Entre los 8 documentos conservados en la Alberca en este siglo ninguno sobrepasa el año 1804. Se mencionan 3 remudos de los llamados "de desposados", uno de ellos valorado en el subido precio de 130 reales, con 6 botones de plata, seguramente repartidos entre los aujales del camisón y los del calzoncillo. También 4 camisas nuevas,

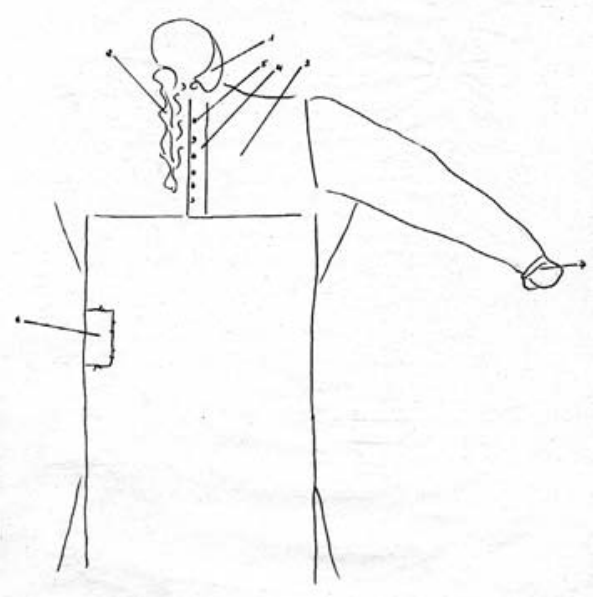

FIGURA 10.-Camisón, siglo XIX: 1, cuello; 2, papera; 3, pechuga, generalmente de lienzo; 4 , pechuga o parte de la pechera que va laboreada con un trabajo conocido como transparente; 5 , botones: dos de oro o de plata bañada en el cuello y diez en la "pecherá"; 6, asiento; 7, puños, anchos o angostos. La guarnición suele ser de vainillas o vainica, terilla, deshilados y puntas. Dibujo A. Cea.

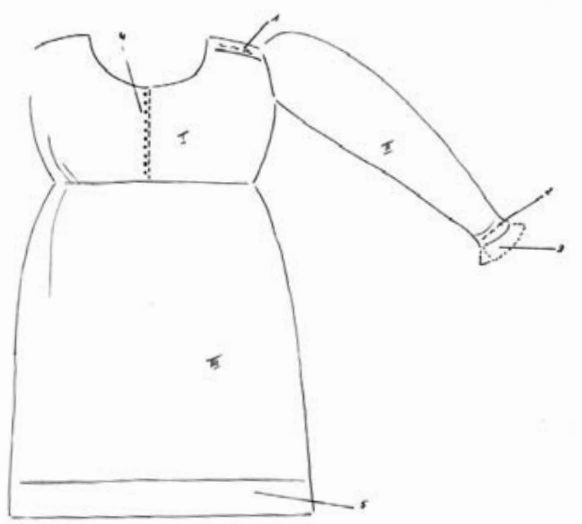

FIGURA 11.-Camisa de mujer, siglo XIX. I. Cuerpo: 1 , hombreras, con o sin labor; 4 , botones (de plata y diamantes en la variante que aparece como "de charra"). II. Mangas, llanas o labradas; 2, puños, generalmente bordados; 3, bocamangas. III. Faldas o árbol; 5, ruedo o rodo.

\footnotetext{
${ }^{14}$ No se conserva de estos años documentación notarial de Sequeros, villa cuyos fondos archivísticos tanto enriquecieron, siglos atrás, la indumentaria serrana, y es prácticamente inexistente la documentación en Mogarraz, que atesora, en cambio, una muy abundante y rica colección de joyas y prendas-testigo. Solamente figuran los protocolos 7986 y 7987, del escribano Francisco González Huebra, correspondientes a los años 1862-1863 y 1864.
} 
labradas con hilo azul, apreciadas cada una en 35 reales. Por último, un cuerpo perteneciente a camisa de mujer con sus mangas bordadas, y otra camisa de mujer, ambas con labores colchadas o "conchadas" en sus cabezones, de lana negra y tasadas cada una en 50 reales.

\section{Candelario}

Concluimos la documentación candelaria del siglo XIX sintetizando los copiosos resultados en esa villa -168 casos - que llegan al año 1873. Las fábricas elegidas para la camisa son el lienzo en 6 ocasiones sin especificar calidad ni procedencia; el hilo de la Coruña, 17 veces; el lienzo casero, otras 17 y el lienzo fino del país, llamado también lienzo superior, con 3 ejemplos; el antiguo lienzo ordinario, conocido como bocadillo, una única vez. En segundo lugar, el algodón en 6 ocasiones y en 2 inventarios, el percal.

Como elementos o partes de la camisa se citan las faldas o falda, el ruedo y el árbol, del que se dan hasta 8 ejemplos y su precio: por un árbol 14 reales y por 3, 84. La ombrera ${ }^{15}$ u ombreras; los puños; el asiento o remiendo. Por un asiento de camisón se pagó la nada despreciable cifra de 10 reales. Finalmente, los botones: botones de puño ( 3 en cada uno), botones de plata de remudo, sin especificar número y, en 1865, camisa de boda con botones de diamantes para la pechera", tasada en 320 reales, entre los bienes y capital entregados por Francisco Sánchez Vallejera a su esposa D a Petra Martín Bejarano (AHPS. Prot. 7751, ff: 150-154). Por el contexto, creemos que se trata de una variante "a uso de ciudadanos" porque se incluye en el lote sombrero de copa, levita, pantalón, corbata, y gorra de uniforme.

Los diversos tipos de guarnición apenas se determinan: "camisa con su lavor" (una sola vez); "camisa con puntas", "guarnecida con puntas" o "camisones apuntados" (en 6 ocasiones), y un ejemplo de "camisa con terilla angosta".

Los precios oscilan entre los 3 y los 7 reales en las hechuras de niño, y entre los 12 y los 50 reales los ejemplos de adultos, según su estado de conservación y la calidad, llegando en casos excepcionales a alcanzar los 80 reales «un camisón de lienzo fino del país, superior". Se trata en este caso de un camisón en remudo para días señalados ${ }^{16}$.

La moda de la camisola está también presente en esta población en 2 ejemplos, el primero en el año 1865, testamento de Doña Antonia Rico López ${ }^{17}$ : "una camisola de tela y pechera, 60 reales" (AHPS: Prot. 7751, f.24v). El otro ejemplo corresponde a la dote de Bernardo Curto Montero a su mujer, Valentina Rico Martín en 1873 (pariente también del abajo citado choricero): «3 camisas en buen estado y una camisola, 30 rea-

\footnotetext{
${ }^{15}$ En 4 ocasiones aparece en un testamento de 1804 la expresión "ombrera" referida a la camisa: "una camisa ombrera, 12 y otra camisa hombrera, 12". De nuevo se cita en el año 1812 una "Camisa de hombrera, 20 y camisa hombrera, negra con su lavor, en 25 reales". Finalmente en 1846 "2 camisas hombreras en 8 reales". ¿Habría que interpretarlo no como un elemento o pieza, sino, más bien como expresión local de la variante de hombre, como cuando se dice: "Un asiento de camisa de hombre", opuesto a "un árbol de camisa de mujer»? A veces nos queda en los documentos una indefinición a la que es difícil responder.

${ }^{16}$ El día de Santa Ana, patrona de esa población, es una de las fechas en que se especifica que "es señalado regalar", como las de san Juan, la de los Pregones, etc.

${ }^{17}$ Es descendiente de Pedro Rico, el choricero de Candelario", inmortalizado por Bayeu.
} 
les cada una" (AHPS. Prot. 8132, ff: 64-67). En Candelario, en el año 1861, llegan a acumularse hasta doce ejemplares de camisa en un solo inventario, la dote de Francisco Antonio Rico: "12 camisas de hilo de la Coruña y caseras, 280 reales" (AHPS: Prot. 7710, ff: 127.134).

En cuanto al estado de conservación de las piezas se mantienen las expresiones "en buen uso"; "usada"; "andada"; "demediada"; "nueva"; "vieja".

Además del precio de la prenda se dan ejemplos del coste por su hechura, de manera inclusiva en unos casos y en otros de modo más generalizante. En documento de donación propter nuptias se lee: "40 reales de las hechuras de las ropas". En dos de ellos de manera explícita: "camisón de lienzo del país con la hechura, 80", o "de pagar la hechura de dos camisones y dos almillas, 11 reales de vellón".

Respecto a la ritualización con queda señalada la prenda, en este caso la camisa o camisón, los de Candelario puntualizan, si cabe más que los serranos. Así encontramos las siguientes acotaciones de circunstancia: "De la dote del padre" o "de la madre»; "dádi-

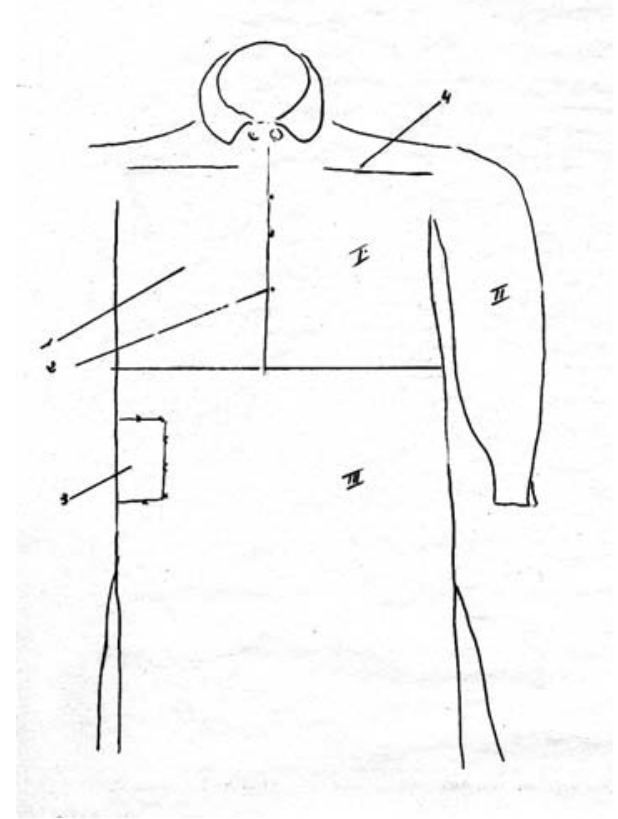

FIGURA 12.-I: Cuerpo; 1, pechera; 2, botones; 4, hombreras. II: Manga. III: Árbol; 3, asiento. Dibujo A. Cea.

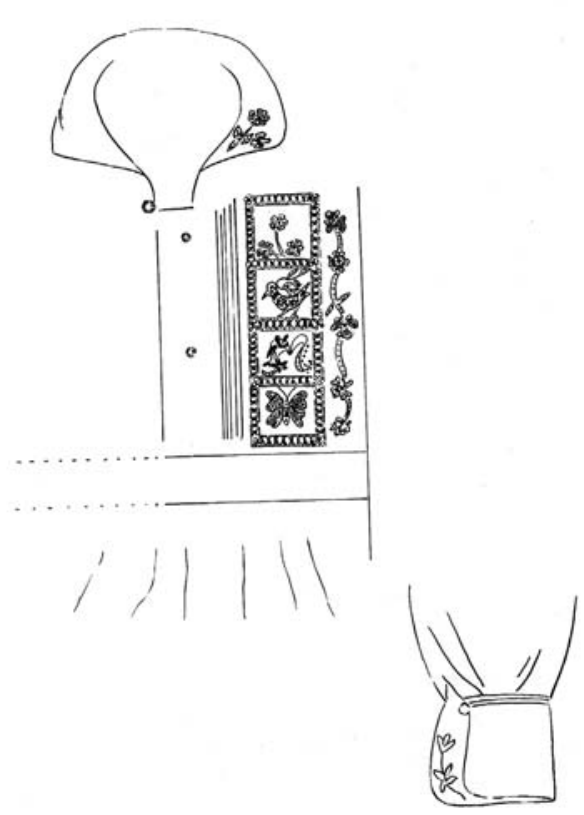

FIGURA 13.-Siglos XIX-XX. Parte delantera: Cuello ancho y bordado, de tipo erudito. Pechera o cuartos delanteros con dos botones de hilo y labor de transparente con motivos de flores, cucos, inicial ( $\mathrm{M} ")$ y mariposa; se protege el transparente con presera y flores. Puño.

Parte trasera: Cuello. Espaldar o cuartos traseros. Mangas y hondillo o sobaco. Árbol. Labores de transparente y bordado erudito. Ambas figuras corresponden a la misma camisa de novio (Mogarraz, col. Cascón Martín). Dibujo A. Cea. 
vas dadas por la novia"; "dádivas dadas por el novio"; "Vistas"; "En vistas que dio a su marido"; "remudo del día de Santa Ana"; "de ofrecijo del tálamo". Otras expresiones son más indefinidas: "al tiempo que se casó"; "que llevó al matrimonio"; "propter nuptias"; "en casamiento"; "ropa de boda"; "a favor de su esposo" (Cea 1985a: 151, 170-171).

\section{Las Casas del Conde}

Los últimos tres documentos de Casas del Conde, correspondientes a los años 1800,1803 y 1830, dejan constancia de 3 remudos, dos conocidos aquí como "de boda" o "del día de la boda" completos, uno en 50 reales y el tercero era "del día de los pregones", más 2 camisas de color negro, tasadas en 20 reales cada una.

\section{Cereceda}

El lugar de Cereceda aporta un único documento (ante el escribano de Miranda) en el año 1806. En el testamento de Pedro González se enumera "un vestido completo de sayal par ir a misa" [que incluye] "mandil, manteo [que serían las piezas propiamente de sayal], una camisa [de lienzo y de cerristopa], jugón de paño fino y una cobixa de baieta negra" (AHPS. Prot. 6913, f.138).

\section{Garcibuey, El Madroñal y Pinedas}

En el año 1806 se menciona en Garcibuey, en el inventario de Miguel Payán, ante el escribano de Miranda, "una camisa de mujer, lavrada de lana negra por acabar, tasada en 38 reales" (AHPS. Prot. 6913, f.165).

Formando parte de un remudo de novio, figura en Madroñal, entre las partijas de Francisco y Margarita Sánchez ante el escribano de Cepeda en el año 1821, el remudo del novio que se compone de «un camisón, calzoncillos y almilla de listón de las almoadas" (AHPS. Prot. 6023, ff.ss.) ¿Debemos entender por listón de las almohadas un tipo de fábrica alistonada, muy propia para esa pieza de cama, o que la cinta de atar la almilla al cuello o a la cintura fuera de las que se emplean como cabos para cerrar las fundas de cama?

En documento de Pinedas, ante el escribano de Miranda, año 1833 aparece inventariada una camisa, probablemente de hombre, de las denominadas "de ombreras", tasada en 40 reales (AHPS. Prot. 6918, f.130).

\section{Mogarraz y Sotoserrano}

A pesar de la casi inexistente documentación notarial de Mogarraz en el Archivo de Protocolos de Salamanca, solamente los años 1864 y 1865, se citan en el inventario de Josepha González de 1864 "dos camisas de mujer usadas, tasadas en 20 reales". Si tenemos en cuenta las prendas descritas en el inventario que sigue, es posible que estas dos camisas tuvieran la hechura "a uso de ciudadanas" siguiendo ya la moda europea y las tendencias, nada fosilizantes, y estatus de esta familia en Mogarraz: "gaván negro, en 20 reales; un Frac negro bueno, en 170; un pantalón gris, en 80 y dos chalinas, en 10 reales", entre otras prendas (AHPS. Prot. 7987, f.34v). 


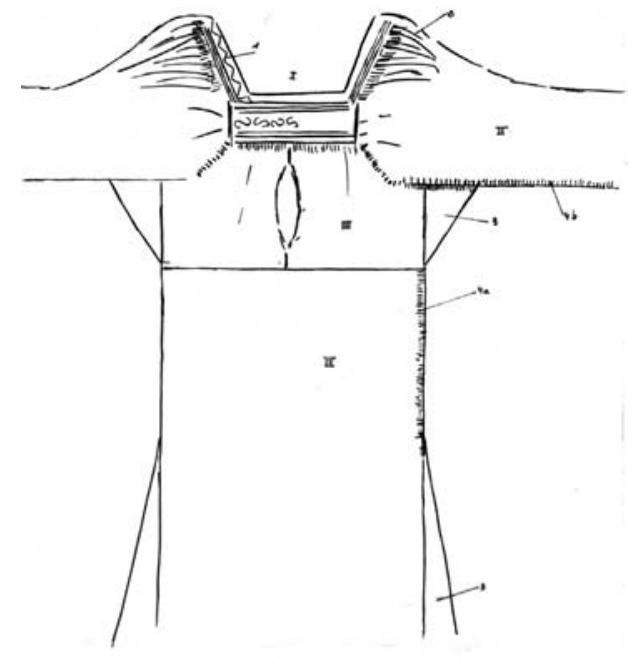

FIGURA 14.-Camisa de mujer, siglos XIX-XX. Vista posterior. I. Cabezón; 1, labor de caireles. II. Mangas; 2, corazón; 4b) costura sevillana. III. Cuartos traseros o espaldar, con sudón. IV. Árbol, generalmente de estopa y el resto, de lienzo; 3, hondillo; 4a) costura sevillana. La guarnición de la camisa es de lana negra de borrega, (La Alberca, col. Rita Hoyos Puerto). Foto A. Cea.

Aunque es exigua la documentación que aporta Sotoserrano sobre la camisa en este siglo (tan solo 4 cartas de dote entre los años 1838 y 1857), se resumen bien las tendencias y características de esta prenda, que continúa en este lugar renovándose. Año 1838: "un camisón nuevo de lienço con desilados, 44 reales; 4 camisas con sus faldas, nuevas, 28 reales" (Dote. AHPS. Prot. 6922, ff: 36-37). Año 1845: "5 camisas nuevas de colchados, 200 reales" (Bienes dotales de Ana Barrio. AHPS. Prot. 6944, ff: 66-71). Año 1857: "Camisa de lienzo nueva de mujer, 20 reales" (Dote de Isabel Rodrigo. AHPS. Prot.7382, ff: 16-22).

En la carta dotal de María Martín González, esposa de Don Alejandro Muñoz, Sargento del Cuerpo de Carabineros del Reino y residente en Sotoserrano, año de 1853, se enumeran hasta 12 camisas: " 4 de color, 48 reales; 2 de lienzo, mediadas, en 28 , y 6 de tela, en buen uso, 84 reales" (AHPS. Prot. 6944, ff: 34-37). Se percibe en esas camisas una proporción de renovado ajuar y un enriquecedor contraste entre las hechuras y labores tradicionales, de lienzos, deshilados y colchados y también la innovación en la utilización de fábricas de "tela" y camisas de color por parte de familias extrañas al lugar.

\section{San Martín del Castañar}

La villa de San Martín, aunque solo conserva 5 documentos sobre la camisa, entre 1804 y 1859, deja entrever en ellos el gusto por las fábricas novedosas que se eligen para su hechura. En la dote otorgada ante el esccribano de Casas del Conde en 1859 por Don Antonio de Moreta a su hija Doña Petra de Moreta, que casó con José María Hernández, natural de Miranda del Castañar, constan "4 camisas de tela [no de lienzo] con sus puntillas, tasadas en 64 reales" (AHPS. Prot.7523, ff: 94 y ss.).

Esa misma tendencia se aprecia en una dote de 1825 donde dice: "una camisa de crea, en 40 reales" (AHPS. Prot. 6216, f.73). En inventario del año 1804 se registran 
dos términos hasta entonces no documentados: "unas mangas de malla de ilo" y "una camisa de bocamanga, sin ruedo" (AHPS. Prot. 6212, f.163) [la negrita es mía].En el año 1808, "una camisa de hombre vordada, en 80 reales" (AHPS. Prot. 6213, f.74). En 1825 entre otras prendas dotales de mujer entra "una camisa de crea valorada en 40 reales" (AHPS. Prot. 6216, f. 73). En ese mismo año, en la dote de esponsales de Leandra Moriente, componiendo un vestido de niño, figuran «una camisa, chaleco, calzones, chaqueta, montera y zapatos, apreciados en 127 reales" (AHPS: Prot. 6216, f.24). Que la camisa es solo prenda de remudo y no se entiende como parte del vestido parece quedar claro en la siguiente descripción del año 1843, "un vestido completo a estilo del país, compuesto de calzón o polainas, chaleco, chaqueta, un sombreo y unos zapatos" (AHPS: Prot. 6940, fs.).

\section{Miranda del Castañar}

En los nueve protocolos del siglo XIX en la villa condal de Miranda, entre los años 1801 y 1858, destaca el florecimiento de una prenda de mujer "a la europea", la camisola o camisolin $^{18}$, variante de camisa femenina y síntesis que resulta del estrangulamiento del rodo - entre otros detalles- en función del ahorro y de la comodidad. Pieza innovadora entre familias de la clase alta mirandeña.

En la dote de Don Mariano de Peña Aceves y María Joaquina Yvancos se citan en el año 1842: "2 camisolines de batista, guarnecidos de crepé, y otros dos de punto, en 280 reales" (AHPS. Prot. 6917, f.161). Igualmente, en inventario de dote que aporta al matrimonio Doña Josefa Ledesma Díez, año 1851, entra un juego de votones para los camisolines, en 30 reales" (AHPS. Prot. 6937, f.42).

En la dote de Manuel Hernández, que casó con Jerónima Sánchez Guinaldo, se mencionan en 1858 "Botones de plata para el camisón en 7 reales y tres camisas de mujer en 30" (AHPS. Prot. 7524, ff: 155 y ss) ${ }^{19}$.

\section{Monforte de la Sierra}

En inventario monforteño de Juana Hernández, viuda de Antonio Cabrera, año 1809, se documenta también "una camisola de tela, en 30 reales y otra camisola de tela buena en otros 30" (AHPS.Prot. 6184, ff: 44 y ss.). Esa misma partida incluye "un camisón bueno de lienzo de cuello ancho para ombre, bueno de lienzo, 24 reales". Otro ejemplar de idénticas características y precio, también de los conocidos como "de cuello ancho" ${ }^{20}$, se registra en esta villa de Monforte (AHPS. Prot. 6184. ff: 60-62v) en ese mismo año. Además de 3 camisones "de los de Novio" o "de Boda", uno de ellos "labrado sin puntas" que se tasó en 90 reales, el otro, en 45 y el tercero, descrito como "Camisón de voda con poca vordadura", en 24 reales, año 1830 (AHPS: Prot. 6186,ff: 245 y ss.). También, "una camisa de mujer, usada y con vocamanga, en 25 reales", año 1809. (AHPS. Prot. 6184, ibid.) ; "una camisa a medio hacer, sin ruedo, nueva,

\footnotetext{
${ }^{18}$ Ya el Cobarruvias describe la camisola como diminutivo de camisa, prendas "que suelen ser labradas y no tienen más que mangas anchas y pechos". Es lo que se diría una pieza "presentada".

19 Deben de ser los dos botones que cierran el cuello del camisón o camisa de hombre, conocidos como de "cabeza de turco", generalmente de plata sobredorada, o de oro.

${ }^{20}$ ¿Estamos ante una fosilizada pervivencia de la valona?
} 
14 reales", año 1823 (AHPS. Prot. 6186, f.112v), y "una camisa de mujer con puños bordados, nueva, en 24", año 1825 (AHPS. Prot. 6186, f.74). Por último, en 1856, "un remudo entero de voda, para hombres, en 30 reales" (AHPS. Prot.7380.ff: 83 y ss.).

\section{Villanueva del Conde}

Esta población de Villanueva, con 17 protocolos, entre los años 1800 y 1835, iguala en este siglo la florida guarnición bordada de "ramos" de que ya había hecho gala en el XVIII con 3 ejemplos de camisa, en 1808 y 1812, tasadas cada una en 30 reales. Se describen 3 camisas de mujer sin rodo o ruedo, más otra, también de mujer, con él, lo que nos recuerda la presencia de este elemento "de cintura para abajo" tan característico.

En el inventario de Floyrán [sic] Zerezo, año 1835, entra «un camisón de puños anchos y papera, en 20 reales" que mantiene la fórmula dieciochesca (AHPS. Prot. 6924 sf.).

Se conservan en Villanueva 4 ejemplos de camisones de boda, uno de ellos "por estrenar" y otro "de los Pregones". Estas variantes de calidad para día de galas, llegan en esta villa a cifras que oscilan entre los 54, 60, 80 y 90 reales, hasta alcanzar en el ejemplar más subido los 150 reales. Se menciona también una camisa de niña, valorada en 10 reales, de la que se dice que es "de negro", quizá refiriéndose al bordado, o al color de la propia prenda si estuviera la niña gastando luto.
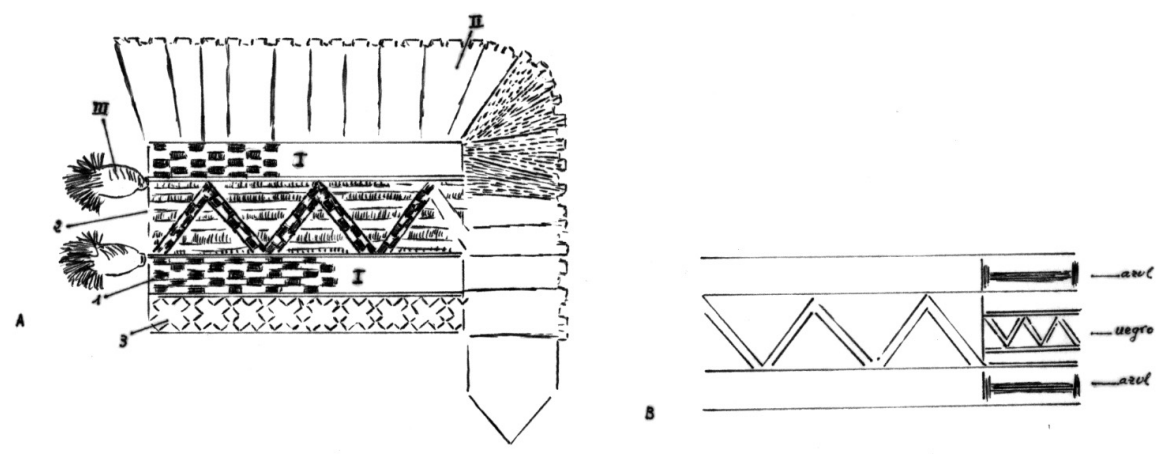

FiguRA 15.-Prenda-testigo de camisa galana, detalle de los puños. A) Elementos de la cara anterior: I, "Careles" [sic]. II, Puntas negras de lana de borrega. III, Botones denominados "de grano de flor de malva" con sus dos elementos: a) "pezón" (azul); b) "fluecos" (encarnados). Labores: 1, Punto de "ladrillo"; 2, punto de lomo"; 3, labor de "real de cuadros". Cara posterior: "Aujales" [sic], dos en color azul y caireles ${ }^{21}$ negros (La Alberca, col. Rita Hoyos Puerto). Dibujo A. Cea.

${ }^{21}$ Cobarruvias describe el cairel como "un entretexido que se echa en las extremidades de las guarniciones". El verbo echar se mantiene entre las serranas como sinónimo de bordar, especialmente si se trata de labor de sobrepuesto: "le eché una greca al manteo". 


\section{Cepeda}

Sin pretender siquiera de lejos las cifras de los siglos precedentes, la villa de Cepeda, con 69 ejemplos sobre la camisa en este siglo XIX es, después de la de Candelario y por la información que aporta, la segunda en importancia.

La carta de dote, en 1821, que Don Francisco Sánchez da a su hermana Doña Wenceslada, es una muestra excepcional de las nuevas tendencias de las camisas que están apareciendo, tanto en su fábrica como en sus colores, además de constatar la fijación - fosilizada - del traje tradicional en la llamada variante charra. Enumeramos tan solo las camisas presentes en este documento:

— «Una camisa elástica de algodón, 80 reales; una camisa de china (Cea 2004b: 243-272), de color aplomado y flores, negra, en 50; camisa nueva de terciopelo de flores, negra, 240 reales; una camisa de alepín, negra nueva, en 150 reales; una camisa de percal, nueva, color café, 30 reales; 3 camisas de uso, buenas, a 20 reales cada una". Entre ellas se nombran "otros pendientes de hechura moderna, en 60 reales" y, por último "una camisa de charra, con 10 botones de plata, en 32 reales", que es prácticamente lo que vale la de percal (AHPS: Prot. 6023, ff: 26 y ss.).

Tenemos, pues, aquí tres tipos de camisa que señalan tres momentos de la moda y del calendario diario y festivo: las camisas que se conocen como "de uso", que serían las cotidianas, las que se estilaban gastar en su tiempo y la camisa que en el inventario se denomina "charra". Me atrevo a decir que en este contexto la voz "charra" debe entenderse, no como la camisa y traje que identifica esa determinada comarca salmantina de la Charrería, bajo cuya voz se incluye el propio traje de la ciudad de Salamanca, sino como sinónimo de camisa correspondiente a traje identitario in genere, ya fosilizado y en uso solo para rituales, distintivo de esa localidad y de la comarca serrana. Sería término semejante al que se conoce en Mogarraz como "los majos", "ponerse los majos" y en Miranda como "de los días de comer fideos", ropa antigua y de fiesta.

Entre los bienes que aporta, la tal Doña Wenceslada, figura también «un camisolín, en 8 reales", 'modernez' también presente en el inventario de Pedro Conde Marcos, año 1815: "2 camisolines" junto a un frac, una casaca, dos chupas y un par de pantalones de punto (AHPS. Prot. 6024, f.s.).

Queremos señalar como contraste en esta villa de Cepeda — de apasionantes ejemplos innovadores en medio de su probada tendencia a arcaizar-, la coexistencia de estas variantes a la moda europea, que acabamos de mostrar, junto al uso de valonas, bragas y calzas en inventarios de 1806, 1826 y 1851 respectivamente: "una Balona de nobio" (Inv. De Manuela González. AHPS. Prot. 6020, ff: 4 y ss.); "una valona de ruan, 2 reales" (Partijas de Sebastián Díaz y Petronila Martín. AHPS. Prot. 6024, fs.); "una valona con encajes, 2 reales" (Inventario de Francisco Gascón. fs.).

En cuanto al número que alcanzan en Cepeda las camisas por ajuar tenemos los ejemplos siguientes: "6 camisones nuevos en 162 reales", año 1808 (Carta dotal. AHPS. Prot. 6020, ff: 103 y ss.); año 1844, "5 camisas de mujer, 3 nuevas y 2 usadas, 120 reales" (Dote de Mํㅡㄹ Antonia Guinaldo. AHPS. Prot.6096, ff: 123 y ss.). Finalmente, "12 camisas labradas de negro, en 300 reales", año 1830 (Dotal de Isabel Sánchez Sánchez. AHPS. Prot. 6904, f. 67). 
Se mantienen las labores colchadas en dos camisas de mujer nuevas y estimadas en 40 reales (año 1845). También, "lavores en la pechuga" en un camisón de lienzo usado que se tasó en 5 reales. Igualmente, se conserva, la guarnición de vainicas en inventario de Francisco Gascón, año 1851: “camisón de lienzo nuevo con vainillas, con 10 botones de plata afeligranados y 2 de oro al cuello, en 80 reales y 2 calzoncillos de lienzo con vainillas, en 20 reales" (Testamento de María Leonís. AHPS: Prot. 6934, f37). El uso de los botones en la camisa se repite en la dote de Catalina González, año 1808: «4 botones de camisa en 12 reales", se supone que de metal.

Los términos "camisón de novio" y "camisón de boda" se recogen 3 veces en este siglo y 14 , los ejemplos de camisas negras.

Como curiosidad, que muy pocas veces se facilita, están los precios por hacer diversas prendas en Cepeda, año 1825, en documento de herederos de Marcos Conde: "La hechura de un jubón a Micaela [¿̇costurera?], 28 reales; la de unos zapatos, 18; la de un manteo, 44 y la de un serenero ${ }^{22}$, 7; la de una camisa nueva, 30 y la hechura de un camisón, al hijo de Marcos, 12 reales”²3 (AHPS. Prot.6024.ff: 67 y ss.).
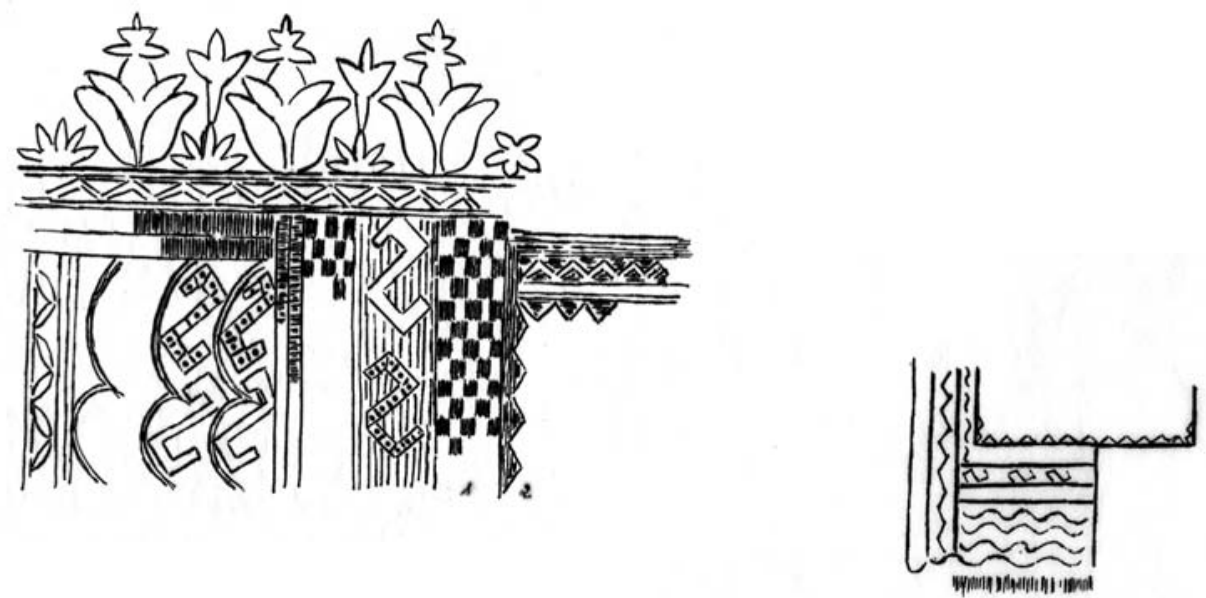

FiguRa 16.-Prendas-testigo. Pecheras de camisa galana, dibujo A): 1, labor de "torritas y campanarios"; 2, caireles. B) 1, "careles"; 2, labor de real o alemanisca con la variante que se conoce en la Sierra de Francia como "de panza de vaca" y medias esvásticas. Ambas pecheras están bordadas con lana negra de borrega (La Alberca, col. R. Hoyos Puerto). Dibujo A. Cea.

\section{CAMISAS "A LO DIVINO"}

Los testimonios documentados de camisas "para vestir santos", principalmente en imágenes vestideras de María y el Niño Jesús, en libros de fábrica parroquiales y otros de cofradía, entre los siglos XVI y XIX, son tan atractivos como escasos. Unas veces estas piezas se confeccionan ex novo para esas advocaciones o, bien, se adaptan las

\footnotetext{
${ }^{22}$ Las mujeres de Mogarraz, Miranda y Cepeda denominan hoy "Senero" al serenero.

${ }^{23}$ Suelen figurar los precios de hechura en cartas dotales y de Vistas
} 
propias prendas de los donantes ofrecidas ahora "en manda"; ejemplos de los que queremos dejar aquí una sintetizada constancia ${ }^{24}$ (Cea 1992: 37-46 y Bernis 1970: 193-218). Estos ajuares litúrgicos, especialmente los de uso festivo, al igual que los de cada familia, se conocen como "los majos". Así figura en Santibáñez de la Sierra en el encabezamiento de las Cuentas del Cristo para el año 1847: "... de los Majos que tiene el Santo Cristo" (APSt. Libro de cofradía del Santo Cristo de 1728, sf.).

En el año 1690 figuran en Cepeda, en colección doméstica (Cea 1993, f.146) «una Imagen de Nuestra Señora con su vestido y un Niño Jesús con su peana y camisa y baquerito". Se trata de unas piezas vestidera, de devoción doméstica, descritas en el inventario por muerte del licenciado y presbítero Don Manuel Pérez de Toribio ${ }^{25}$ (AHPS.Prot. 5993, f.146).

En el año 1727 constan en el ajuar del Niño Jesús del Rosario de la parroquial de Linares "Tres casaquitas del Niño y una camisita con encajes blancos" (APL. Fábrica de 1727, f.104).

Entre las alhajas de la Virgen de las Nieves de Mogarraz se cuentan en 1789 "dos camisas de Nuestra Señora y dos del Niño, biejas" (APMํo, Fábrica de 1737, f. $401 v)$.

También el inventario del Dulce Nombre de Jesús en Casas del Conde, año 1737, refleja la presencia de esta prenda — «tres camisitas de lienzo mediado" - para vestir la imagen patronal de esa cofradía, fundada en 18 de enero de 1629 (ADS, 177/29, ff: 42-43).

En el año 1883 y para la imagen de Nuestra Señora del Rosario, en la parroquial San Martín del Castañar, se hizo donación de "5 tocas de camino, grandes y pequeñas, más 6 camisas, las dos mui viejas" (APSMtn. Fábrica de 1617, Inventario de Nuestra Señora del Rosario,sf.). Para la del Dulce Nombre de Jesús, venerada con altar pro-
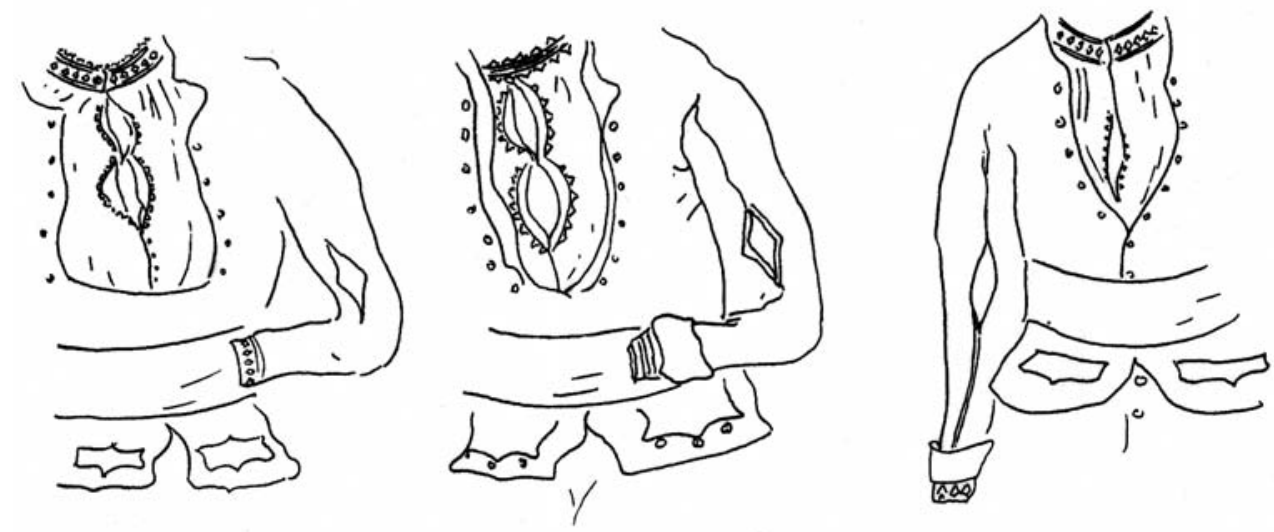

FiguRA 17.-Detalles de camisones masculinos bajo jubones, tomados de grabados según Cano y Olmedilla, Laroque y Albuerne sobre tipos salmantinos. Dibujos de A. Cea.

\footnotetext{
${ }^{24}$ Cea Gutiérrez, A. 1992. Religiosidad Popular. Imágenes Vestideras. Zamora: Caja España.

${ }^{25}$ AHPS, Prot .5993, f.146. Cea Gutiérrez. A. 1993. "Coleccionismo y devociones domésticas en la Sierra de Francia y Candelario (Salamanca, siglos XVII-XIX". RDTP XLVIII: 213-288.
} 
pio en la parroquial de Monforte, se mandó en el año 1624 «una camisa delgada [...] más una valona con su encaxe" (APMf. Libro de Alajas del Dulce Nombre de Jesús, sf.) En 1831 vuelven a nombrarse en el mismo libro y para la misma imagen "un escote bordado de banco y encarnado y dos camisas" (ff.38-38v).

Finalmente en el año 1873 se mencionan en el Libro de Cofradía del Rosario de Tamames, entre otras prendas "la camisa y enaguas" de esa imagen vestidera (APT. Fábrica de 1873, fs.) .

\section{CONSIDERACIONES FINALES}

A través de la documentación de archivo hemos tratado de exponer las características técnicas y formales de la camisa y sus variantes en un ámbito rural donde importa mucho - en lo personal y en lo familiar - la indumentaria como lenguaje social, pero también, el uso y el destino que dieron a esas ropas quienes las confeccionaron, vistieron, disfrutaron y, finalmente, heredaron.

Algunos ejemplos del refranero (en este caso el del Maestro Correas, en el entorno salmantino del siglo XVII) subrayan la importancia - y las claves morales- que encierran los refranes y las frases proverbiales que el vulgo utilizó a diario, refranes que eran tenidos por el pueblo como "los evangelios chiquitos", en especial los relativos a la camisa (Cea 2002:116-120).

Por medio de la iconografía en esculturas, pinturas, grabados y dibujos, hemos pretendido facilitar la comprensión de unos materiales protocolizados, de los siglos XVI al XIX, interpretando con formas lo escrito en documentos. Para completar la terminología en los esquemas dibujados de la camisa, incorporamos voces recogidas de los informantes (especialmente de la Alberca) que no parecen acreditadas en la documentación de archivo. Es el caso de los términos nesga, corazón, costura sevillana, botón de los de flor de malva y sudón ${ }^{26}$.

A la hora de materializar los resultados de la investigación hemos tenido que conjugar a veces el interés de la información documental cuantitativa acumulada y la conveniencia de sacrificar la abundancia para ofrecer un producto menos pormenorizado pero más claro.

Describimos la evolución de la camisa en dos comarcas salmantinas, La Sierra de Francia y Candelario durante cuatro siglos, señalando las sutiles diferencias locales de las distintas clases sociales y de los pueblos entre sí. El desplante que sufrió la camisa por el esplendor del jubón en los siglos XVIII y XIX provoca la mengua documental, constatada en los inventarios de ese último siglo, convirtiéndose, una pieza tan necesaria, en algo que podemos considerar residual, al menos en la variante de mujer. Las versiones de trajes femeninos que reconocemos hoy como "de manteo", "Sayas", "Vistas", "Ventioseno" (no digamos las variantes que utilizan el pañuelo de Manila) no admiten, por innecesaria e incómoda, la camisa (Cea 2004b: 243-272).

La práctica extinción del sayuelo en el siglo XVIII arrastró la de la camisa, estrangulada bajo la opresión del jubón (jugón o jugona). La holgura y visibilidad que ofrecía el

${ }^{26}$ Es la cuchillada o abertura en el espaldar de la camisa de mujer, presente también en la jugona o jugón como respiradero. 
sayuelo a la camisa de mujer como un transparente, a través de los cabezones, porteras, mangas y bocamangas, especialmente durante los siglos XV y XVI, favorecía el lucimiento de la camisa, en ocasiones hasta rayar en la extravagancia, con sus diversas maneras de asomarse al exterior formando cuchilladas, bocadillos, folladuras y borrachas. A ello se prestaba, además, la personalidad de las mangas, entonces prenda independiente, en su doble fórmula -incorporadas y cosidas a los cuerpos, o solo atadas a ellos- con sutiles "puentes". Las puntas y encajes (postizos o "puestizos") de las bocamangas que el jubón añadió, tal como los vemos hoy, son en realidad un trampantojo, igual que las cortapisas en los manteos de Vistas. Son el resultado fagocitario del jubón, que colonizó y asfixió a la camisa. Conviven aún, en cambio, jubón y camisa en Peñaparda (Ortiz Echagüe 1971: 136, 145, 147-148).

He de decir que, desde mi experiencia en trabajo de campo, la camisa de mujer es hoy una de las prendas-testigo más escasas de la indumentaria salmantina. Los ejemplos que perviven son sobre todo los de la camisa de galas, más llamativas y ornamentadas. Como en cualquier prenda, también en esta se ofrecen ejemplos de reutilización por desuso y a veces por necesidad ${ }^{27}$.

Es hoy reducido el uso y la visibilidad de la camisa de mujer en la indumentaria de Salamanca, conocida genéricamente como camisa "galana" y suele ser complemento del zagalejo en tierras de la Armuña, Alba, algo en la Ribera, Ramajería, Robleda y Peñaparda ${ }^{28}$.

Las piezas-testigo de la camisa de mujer que conocemos corresponden a ejemplares de días de galas y por ello ricos en su fábrica, con todos los elementos de lienzo de primera calidad y guarnición en cabezones, mangas y puños, con bordados en lana o lanilla, casi siempre negra, rara vez de labores blancas y azules, y motivos geométricos, zoomorfos y fitomorfos, mostrando en algunos ejemplares un verdadero horror vacui en porteras y mangas. La mayoría de las hoy piezas-testigo se abrochan con botones llamados "de flor de malva" y algunas, con los de filigrana de plata, seca, o ahumada.

En el traje de hombre ha prevalecido el uso de la camisa o camisón. La variante de Candelario, igual que la de la mayoría de las comarcas salmantinas, utiliza la hechura del cabezón redondo — reliquia de lo que fue lechuguilla- con porteras o cuartos delanteros. En el camisón serrano, en cambio, la versión adoptada es la que derivaría de la fórmula (posterior) de la valona.

El "Colorín colorado..." a lo largo de este recorrido diacrónico es que, desde finales del siglo XVIII y a lo largo del XIX, por las razones arriba aducidas, las camisas de mujer que se mencionan en los documentos como "antiguas" o "muy antiguas", algunas de ellas de los siglos XVI y XVII, fueron quedando preservadas por desuso en las arcas. Así han llegado a nosotros las piezas más deslumbrantes de cuantas ha habido en la indumentaria tradicional española.

\footnotetext{
${ }^{27}$ Conocemos un ejemplo albercano de tres mangas de camisa labradas que formaban parte de unos antelechos. Hemos oído contar en numerosas ocasiones cómo la práctica desaparición de la anguarina serrana se debió a su transformación en falda de las mesas camillas durante las posguerra (Cea 2004a: 141-145).

${ }^{28}$ En los últimos años y por diversos motivos socioculturales ha resurgido en Salamanca el gusto y uso de la camisa galana (prenda de mocedad) predominantemente por las mujeres de edad.
} 
Cuesta imaginar que las gentes serranas, en especial las de Mogarraz y la Alberca, vistieran otras fórmulas distintas a las fosilizadas que conocemos hoy y que operan cognitivamente en nosotros como estereotipos identificadores de una realidad para nosotros inamovible y fija.

Ante este tipo de estudio diacrónico (podría decirse arqueológico) surge la problemática de la compensación o, mejor, de la descompensación de las fuentes, las distintas fuentes documentales en las poblaciones donde bebemos para la reconstrucción de la indumentaria, en este caso de la camisa. No manan siempre, ni a la vez, ni continuamente, ni con la misma intensidad, calidad y cantidad, y a veces se secan y desaparecen.

De entre las 20 poblaciones con documentación sobre la camisa, solo la Alberca, Cepeda y Sotoserrano mantienen la continuidad desde el siglo XVI al XIX. En pocas ocasiones podremos decir que el caudal documental, iconográfico, de piezas-testigo y tradición oral esté equilibrado. El ejemplo más llamativo es el de Mogarraz que, siendo con la Alberca la población que más piezas y de mejor calidad atesora, conserve solamente protocolos notariales (y estos escasos), entre los años 1864 y 1865.

Hemos de ser conscientes de que los resultados, por muy completos que nos parezcan, son siempre parciales. Ni todo el mundo testaba ni, habiendo testado, todos los documentos se conservan. Obtenemos, pues, un mosaico fragmentado y a veces descontextualizado que, no obstante, ayuda a recomponer cada realidad.

La mayor riqueza documental — que es la fuente que más ayuda y la única que proporciona seguridad científica- coincide en estas dos comarcas salmantinas (La Sierra y Candelario) en los siglos XVII y XVIII:

Como en pocos ejemplos es posible en este de la camisa reconocer o recorrer la evolución en la indumentaria, seguir las corrientes de la moda, los gustos, el estatus social personal y familiar, al ser la camisa una prenda tan esencial (diríamos hoy 'básica') y probablemente la más compleja en su arquitectura de elementos y, por tanto, en la riqueza de su léxico.

Aún quedando abundantes lagunas por completar, hemos logrado identificar todas las parcelas estructurales y recuperar los términos - generales y locales-, los elementos esenciales y los de detalle. También, ofrecer la variada floración de los temas ornamentales y de guarnición de esta prenda.

Por lo general, los investigadores y estudiosos de la indumentaria hemos atendido más a la reconstrucción, retrato de la pieza, prenda o alhaja, en este caso la camisa, que a la de la sociedad que la disfrutó: ¡cómo nació, cuándo se utilizó, cuántos cuerpos vistió, dónde se ubicaba cuando el tasador se ocupó de inventariarla, o si afortunadamente, pasa el túnel del tiempo y llega a nuestras manos. En algún caso (raro y felicísimo) hemos logrado identificar la pieza documentada perviviendo como pieza-testigo.

Es necesario destacar la convivencia armónica de distintas tendencias. En una misma población comparten espacio y tiempo las camisas que han llegado a nosotros como "antiguas" o "muy antiguas", las que se aceptaron como "propias del lugar" o " al uso del país" o "como se estila gastar" y aquellas otras, novedosas, "a uso de ciudadanos". La camisa aparece documentada como conjunto de elementos formando un todo y también como piezas "de por sí", desmembradas y siempre con identidad propia, como pequeñas islas, probablemente no salidas del mismo hilo y aguja, hasta encontrarse 
un día compartiendo un todo unitario. Hablo de los cabezones, los puños, el cuello, las porteras y el rodo. En el caso de las mangas resulta más comprensible porque durante un largo periodo fueron prendas independientes.

Además de las labores bordadas en lana y lanilla negra, que son las variantes que han prevalecido, hemos de resaltar el uso de la seda, también negra, como guarnición, y la presencia del blanco y otros colores (encarnado, amarillo, caparrosa verde y azul) como opciones alternativas. El empleo durante los siglos XVII y XVIII del amarillo, casi como variante local en las camisas de San Martín del Castañar y, sobre todo, la posibilidad de otros colores y materiales que no sea el lienzo blanco en la tela de las camisas: negras, azules, color café, son algunas de las aportaciones más novedosas de este estudio.

Hemos de subrayar la tendencia en Cepeda a fosilizar y al uso del color encarnado como predominante en las prendas; o el gusto en Villanueva del Conde por la ornamentación abigarrada (casi excesiva) con motivos de "ramos" y "ramos y cuecos" bordados, de gran tamaño ${ }^{29}$ (Cea 1985: 21-68). Igualmente, la fuerza vanguardista de la moda entre la nobleza y el funcionariado en Miranda del Castañar, que acoge la novedad de la camisola o camisolín, en los siglos XVIII y XIX.

Es significativa (y a veces muy sutil) la percepción de contraste sobre lo propio y lo extraño en el análisis de la documentación de Candelario respecto a la de la Sierra de Francia al describir cierta prendas, en ocasiones con términos excluyentes para su denominación, diferencias evidentes también en el minucioso protocolo candelario de regalar en días señalados durante el noviazgo y en la boda. Igualmente, a la hora de indicar en los inventarios el consumo de lo 'otro cercano', especialmente piezas de mobiliario y aperos (cunas, arcas y cestos) verbalizando la diferencia como "serrana" al nombrar su procedencia.

El empleo del término "antiguo" o "muy antiguo" como valor en sí y muy distinto al de "viejo" explica la convivencia, en el caso de la camisa, de piezas con fórmulas arcaizantes, junto a otras actuales y "a la moda europea", como sucede con el caso de la valona, prenda que llega viva y en uso al siglo XIX. Se documenta en 1802 en una carta dotal de la Alberca, "Valona de nabal con su cordón de seda, 8 reales" (AHPS.

\footnotetext{
${ }^{29}$ Fenómenos que ya observamos al estudiar el traje de luto en la Sierra de Francia
} 
Prot. 6126, f.157v); también en Madroñal, año 1821 en las partijas por muerte de Margarita Sánchez, viuda de Francisco Guinaldo, donde se tasaron "dos valonas en 2 reales" (AHPS: Prot. 6023. ff.ss.).En Garcibuey, año 1803, se cita "una valona de ruan con encajes, en 4 reales", en el inventario de Antonio González ante el escribano de Miranda (AHPS. Propt. 6157, f. 233). Un año después en ese mismo lugar y ante el mismo escribano se tasan "tres valonas, dos de voda y una de luto, en 12 reales" (AHPS. Prot. 6157, f. 251). Finalmente, "una valona con encajes, 2 reales" en Cepeda, año 1851, inventario de Francisco Gascón (AHPS: Prot. 6934, fs.). ¡Fenómenos de pervivencia que no dejan de asombrarnos!

\section{BIBLIOGRAFÍA CITADA}

Bernis Madrazo, C.1957. "Indumentaria Española del siglo XV. La camisa de mujer». Archivo Español de Arte XXX: 187-209.

Bernis Madrazo, C. 1970. "la moda y las imágenes góticas de la Virgen. Claves para su fechación". Archivo Español de Arte XLIII: 193-218.

Bernis Madrazo, C. 1978. Trajes y Modas en la España de los Reyes Católicos. I: las Mujeres. Madrid: CSIC. Instituto Diego Velázquez.

Bernis Madrazo, C. 1979. Trajes y Modas en la España de los Reyes Católicos. II: Los Hombres. Madrid: CSIC. Instituto Diego Velázquez.

Casado Lobato, C. Cea Gutiérrez, A. y F. Rodríguez Pascual. 1986. Tipos y trajes de Zamora, Salamanca y León. Acuarelas de la Escuela Madrileña de Cerámica (prólogo de J. Caro Baroja). Zamora: Caja Zamora: 117-185.

Cea Gutiérrez, A. 1982. "El cultivo del lino y los telares en la Sierra de Francia, Salamanca”. Revista de Dialectología y Tradiciones Populares XXXVII: 161-198.

Cea Gutiérrez, A. 1983. "El traje de los alrededores de Salamanca como lo vieron los grabadores de los siglos XVIII y XIX", en Revista de Folklore 36: 183-194.

Cea Gutiérrez, A. 1985a. Guía de las artesanías de Salamanca. Madrid: Ministerio de Industria y Energía y Diputación de Salamanca: 9-211.

Cea Gutiérrez, A. 1985b. "Los ciclos de la vida: Ritos y costumbres en torno a los difuntos en Salamanca". Revista de Dialectología y Tradiciones Populares XL: 21-68.

Cea Gutiérrez, A. 1991. "Le costume dans les aires culturelles espagnols: donnés génerales pour l'etude historique du costume", en Deuxième atelier européen "Eurethno" (S. García Mouton, trad.). Estrasburgo: Consejo de Europa: 131-141.

Cea Gutiérrez, A. 1992. Religiosidad Popular. Imágenes Vestideras. Zamora: Caja España.

Cea Gutiérrez, A. 1993. "Coleccionismo y devociones domésticas en la Sierra de Francia y Candelario (Salamanca, siglos XVII-XIX)". Revista de Dialectología y Tradiciones Populares XLVIII: 213-288.

Cea Gutiérrez, A. 2002. "La indumentaria en el refranero de Correas. Retrato y caricatura de la España del siglo XVII", en Moda y Sociedad. La indumentaria: Estética y Poder (M.I, Montoya, ed.). Granada: Universidad de Granada: 101-136.

Cea Gutiérrez, A. 2003 "Al Hombre por el vestido: Supuestos generales para el estudio de la indumentaria" en Es vestir antic. II Jornades de Cultura Popular a les Pitiuses. Ibiza: Conseil Insular: 15-42. 
Cea Gutiérrez, A. 2004a. "lo que vestía Manuel Sánchez, el Mozo de Monleón, la tarde funesta en que un toro le dio muerte", en Salamanca, Revista de Estudios 51. La cultura de tradición oral (homenaje a Ángel Carril). Salamanca: Diputación de Salamanca: 137-147.

Cea Gutiérrez, A. 2004b. «Entre el tópico urbano y la realidad rural. La implantación del pañuelo de Manila en tierras de Salamanca: un caso de globalización localizada", en La ciudad es para ti. Nueva y viejas tradiciones en ámbitos urbanos (C. Ortiz García ed.). Barcelona: Anthropos: 243-272.

Cea Gutiérrez, A. 2005. "Camisa de mujer, de las conocidas hoy en la Sierra de Francia como galanas", en El Quijote en sus trajes (R: Pereda y S. Rodríguez Bernis, coords.). Madrid: Ministerio de Cultura: 206-207.

Cea Gutiérrez, A. 2008. "La belleza pintoresca en la obra de un viajero inglés", en William Bradford: Viaje por España y Portugal. La Guerra Peninsular, 1808-1809 (R. Robledo, ed.)Salamanca: Caja Duero: 33-44.

Giese, W. 1955. "Telares de Astorga". Revista de Dialectología y Tradiciones Populares XI: 3-14.

González Iglesias, L: 1944. El Bordado Popular Serrano. Salamanca: Centro de Estudios Salmantinos.

Lorenzo López, R. y Sánchez Sánchez, M. E. 2006. Vidal González Arenal. 1859-1925. Pintor entre dos siglos. Salamanca: Diputación de Salamanca-Caja Duero.

Ortiz Echagüe, J. 1971 (12. ${ }^{a}$ ed.). Tipos y Trajes (Prólogo de J. Ortega). Madrid: Editorial MAYTE.

Serrera Contreras, R.M. 1974. Lino y cáñamo en Nueva España (1777-1800). Sevilla: Escuela de estudios Hispano-Americanos de Sevilla.

Virgilio Bejarano, F. 1950. "El cultivo del lino en las regiones salmantinas de las Bardas y la Huebra". Revista de Dialectología y Tradiciones Populares VI: 243-263.

\section{FUENTES DOCUMENTALES CONSULTADAS}

Archivo Histórico Provincial de Salamanca (AHPS). Sección Protocolos (Prot.); Archivo Diocesano de Salamanca (ADS); Archivo Histórico Nacional. Sección Clero, Libros; y Libros de Fábrica y de Cofradía Parroquiales en las siguientes poblaciones:

Alberca La. Escribanos: Francisco Martín, Prot.6031; Manuel Pérez Calama, Prot. 6103; Tomás de Ávila, Prot. 6126 y 6127.

Arroyomuerto (actualmente conocido como San Miguel de Robledo). Escribano: Lucas Calbo, Prot. 6198.

Candelario. Escribanos: Marcos Marín, Prot. 1133-1135; Antonio Vallejera, Prot. 11371138,1140-1143; Diego Rico Peña, Prot. 1144; Francisco Sánchez Leal, Prot. 1145; Joaquín Peña Rico, Prot. 1146- 1153; Joaquín Rico Peña, Prot. 1154-1155; Domingo Dueñas, Prot. 7710, 7749, 7751, 8131.

Casas del Conde Las. Escribanos: Luis Corral, Prot. 5976; Pedro José Díaz del Castillo, Prot. 6899, 5979; Santiago del Castillo,Prot. 6900-6901.

ADS. 177/29, Años 1696 y 1737, Libro de Cofradia del Dulce Nombre de Jesús, 16291737: ff: $12-13$ y $42-43$. 
Cepeda. Escribanos: Francisco Hernández Chorrero, Prot. 5981; Antonio Martín, Prot. 59825990; Mathías Panchuelo, Prot. 5991-5994; Francisco Díez Barrio, Prot. 5995-5998; Manuel Martín, Prot. 5999; Sebastián Díez Barrio, Prot. 6903, 6000-6006; Alejandro Panchuelo, Prot. 6007-6015; Pedro González Barrio Cifuentes, Prot. 6016-6025, 69046905; Antonio González Gómez, Prot. 6906, 6933-6934.

Cereceda. Escribano: Phelipe Antonio Coca, Prot. 6913 (ante el escribano en Miranda).

Garcibuey. Escribano: Juan Antonio Coca, Prot. 6150 (ante el escribano de Miranda). Linares de Riofrío. APL., año 1727, Fábrica de 1727, f. 104.

Madroñal El. Escribano: Ceferino González, Prot. 6023.

Miranda del Castañar. Escribanos: Phelipe Antonio Coca, Prot. 6156, 6161; Antonio Hernández Gascón, Prot. 6171, 6915; Manuel Hernández Gascón, Prot. 6917, 69366937; Santos González Gómez, Prot. 7524 (escribano de Cepeda).

Mogarraz. APMo. Año 1789, Libro de Fábrica de 1737, f. 401v.

Monforte de la Sierra. Escribano: Juan Elegido, Prot. 6179. Manuel Panchuelo, Prot, 6184; Manuel Maíllo Hernández, Prot. 6186, 7380.

APMf. Años 1624 y 1831, Libro de Alajas del Dulce Nombre de Jesús, sf.

Pinedas. Escribano: Félix Atienza, Prot. 6918 (ante el escribano en Miranda).

San Martín del Castañar. Escribanos: Juan Calvo, Prot. 6194; Lucas Calbo, Prot. 6195; Gregorio García, Prot. 6210, 6212-6213, 6216, 6940; Santiago Díez del Castillo (ante el escribano en las Casas del Conde), Prot.7523.

APSMtn. Año 1883, Libro de Fábrica de 1617. Inventario del Rosario, sf.

San Miguel de Valero. Año 1581. APS. Miguel. Difuntos de 1572, f. 133.

Santibáñez de la Sierra. APSt., año 1847, Libro de Cofradía del Santo Cristo de 1728, sf.

Sequeros. Escribanos: Antonio Pérez, Prot. 6221-6223; Pedro Fernández de Ynés, Prot. 6224-6228; Francisco Hernández Montero, Prot. 6231, 6234-6236; Domingo Rodríguez, Prot. 6237-6240; Francisco Berrocal, Prot. 6241-6247; Domingo Hernández Muñoz, Prot. 6248-6250; Juan Prieto, Prot. 6251.

Sotoserrano. Escribanos: Alonso Lobato, Prot. 6285-6289; Andrés Pasqual, Prot. 62906292; Domingo Chuche, Prot. 6291-6300; Bernardo Mateos, Prot. 6301-6302; Domingo Gil, Prot. 6303-6308; Miguel de Álvaro, Prot. 6309; Juan García de Álvaro, Prot. 6311-6312; Julián Nieto, Prot. 6313; Antonio de la Presa, Prot. 6314; Fernando Alonso, Prot. 6922, 6944,7382.

Tamames. APT. Año 1873, Libro de la Cofradía de Nuestra Señora del Rosario, fs.

Villanueva del Conde. Escribanos: Fabián Marcos Maldonado, Prot. 6319-6330; Francisco Martín Santos, Prot. 6166 (ante el escribano en Miranda del Castañar); Fabián Marcos Maldonado Cerezo, Prot. 6330-6034, 6924.

Zarzoso. AHN. Sección Clero, Libros: 11153. Cuentas de 1627, f. $15 \mathrm{v}$.

Fecha de recepción: 23 de septiembre de 2014

Fecha de aceptación: 27 de octubre de 2014 